\title{
Ni/HZSM-5 Catalyst Preparation by Deposition-Precipitation. Part 1. Effect of Nickel Loading and Preparation Conditions on Catalyst Properties
}

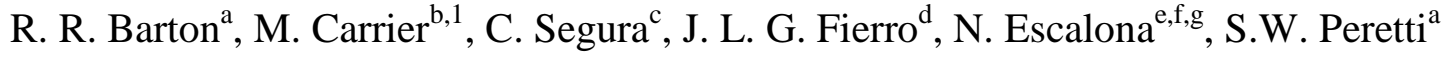 \\ ${ }^{a}$ North Carolina State University, Department of Chemical and Biomolecular Engineering, Raleigh, NC \\ ${ }^{b}$ Universidad de Concepción, Unidad de Desarrollo Tecnológico, Coronel, Chile \\ ${ }^{1}$ European Bioenergy Research Institute, Aston University, Birmingham B4 7ET, UK \\ ${ }^{\mathrm{c}}$ Unidad de Desarrollo Tecnológico, Universidad de Concepción, Coronel, Chile \\ ${ }^{\mathrm{d} I n s t i t u t o ~ d e ~ C a t a ́ l i s i s ~ y ~ P e t r o q u i ́ m i c a, ~ C S I C, ~ C a n t o b l a n c o, ~} 28049$ Madrid, Spain \\ ${ }^{e}$ Pontificia Universidad Católica de Chile, Departamento de Ingeniería Química y Bioprocesos, Santiago, Chile \\ ${ }^{\mathrm{f}}$ Pontificia Universidad Católica de Chile, Facultad de Químicas, Santiago, Chile \\ ${ }^{g}$ Centro de Investigación en Nanotecnología y Materiales Avanzados (CIEN-UC), Pontificia Universidad Católica \\ de Chile, Santiago, Chile
}

Ryan R. Barton:

rrbarton@ncsu.edu

Marion Carrier:

m.carrier@aston.ac.uk

Cristina Segura:

c.segura@udt.cl

Jose Luis Garcia Fierro:

jlgfierro@icp.csic.es

Néstor Escalona:

neescalona@ing.puc.cl

Steven W. Peretti:

peretti@ncsu.edu

\section{Corresponding Author:}

Steven W. Peretti

Department of Chemical and Biomolecular Engineering

NC State University

Campus Box 7905

Raleigh, NC 27695-7905

peretti@ncsu.edu 


\begin{abstract}
Nickel metal supported on HZSM-5 (zeolite) is a promising catalyst for lignin depolymerization. In this work, Ni/HZSM-5 catalysts were synthesized via depositionprecipitation (DP) and characterized. The effect of synthesis parameters; including nickel loading, DP time (synthesis contact time), and calcination temperature, on catalyst properties were studied. $\mathrm{N}_{2}$ and $\mathrm{CO}_{2}$ adsorption techniques were used to look at textural properties and confirmed the existence of lamellar species generated from DP. X-ray diffraction (XRD) confirmed that nickel metal was present on the support after reduction and passivation of the catalyst. Temperature programmed reduction showed that all the catalyst preparations were reducible at $733 \mathrm{~K}$ after $4 \mathrm{~h}$, and that the DP method formed a mixture of $\mathrm{Ni}^{2+}$ species on the support. Transmission electron microscopy, XRD, and $\mathrm{H}_{2}$ chemisorption were used to determine approximate particle size and dispersion of nickel metal. From all the preparations, the $15 \mathrm{wt} \%$ Ni/HZSM-5 catalyst with long DP time $(16 \mathrm{~h})$ and low calcination temperature $(673 \mathrm{~K})$, exhibited the most favorable particle size $(\sim 5 \mathrm{~nm})$ and dispersion $(7 \%)$.
\end{abstract}




\section{Introduction}

Lignin residues are generated as a byproduct in various industries including paper and pulp plants and biorefineries. Currently, the lignin is not utilized to its full economic potential; instead it is burned as low value fuel to power industrial processes [1,2]. Lignin, if processed correctly, could be used for the production of aromatic compounds, platform chemicals, and other high value products, which are also typically derived from petroleum [1-4]. Therefore, converting lignin into aromatic products not only makes cellulose-based industries more economically feasible, it provides a renewable resource for the production of important chemicals. The strategy of interest is the depolymerization of lignin into simple aromatics through the use of a multifunctional catalyst, one capable of hydrogenolysis of both $\mathrm{C}-\mathrm{O}$ and $\mathrm{C}$ $\mathrm{C}$ linkages in lignin, under mild reaction conditions in an aqueous environment. A highthroughput method for testing this catalytic activity is the use of guaiacol hydrodeoxygenation assays, since guaiacol exhibits methoxy and hydroxy moieties, which are C-O bonds found in lignin. While these $\mathrm{C}-\mathrm{O}$ bonds are simpler than the $\beta-\mathrm{O}-4$ linkage and other $\mathrm{C}-\mathrm{O}$ linkages found in lignin, these bonds all need to undergo hydrogenolysis; cleavage via hydrodeoxygenation is a desirable form of hydrogenolysis for the depolymerization of lignin. In this work, a Ni/HZSM-5 catalyst synthesized via deposition-precipitation (DP) is developed for this purpose.

Most literature about the DP synthesis involves silica supports instead of zeolite supports. Therefore, before evaluating the Ni/HZSM-5 catalytic activity against lignin and model compounds, an in-depth study of the DP method was conducted. Burattin et al. [5] studied the effect of DP time and reactant concentrations (silica, nickel nitrate, and urea) on the yield of nickel and the nickel species formed on the support, and proposed a molecular mechanism for the incorporation of nickel onto the silica support. The study observed the formation of nickel hydroxide and 1:1 nickel phyllosilicate species (prior to calcination), where a mixture of the 2 species was observed for low DP times (less than $4 \mathrm{~h}$ ), and solely 1:1 nickel phyllosilicate was observed for long DP times (4-16 h) [5,6]. The standard DP procedure utilized in the Burattin studies were also used to prepare the supported nickel catalysts for the HDO reaction studies mentioned above [7-10]. In those studies, they used different DP times to obtain different nickel loadings, but did not look into the effect of having the presence of different nickel species on a zeolite support, as can be formed with the DP method.

Nares et al. [11] observed the effect of varying DP time from 1-4 h using the standard procedure from Burattin et al. [5] on the catalyst properties including textural properties, nickel particle size, and the nickel species present for Ni supported on $\mathrm{H} \beta$ zeolite. The relationship of DP time to nickel loading/nickel yield was similar to the relationship observed in Burattin et al. [5] using the same standard procedure, despite the use of an $\mathrm{H} \beta$ zeolite support instead of a silica support (both with large surface areas, $580 \mathrm{~m}^{2} \cdot \mathrm{g}^{-1}$ and $400 \mathrm{~m}^{2} \cdot \mathrm{g}^{-1}$ respectively). In the Ni/H study, 3-5 nm nickel particles were formed, a mixture of nickel species was also observed (as was observed in the $\mathrm{Ni} / \mathrm{SiO}_{2}$ catalyst by Burattin et al. [5]), and for both low and high surface area supports, deposition occurred mainly on the external surface [11]. More recent studies have characterized the nickel phyllosilicate species $[12,13]$. In a recent work by Chen et al. [14], they have confirmed the existence of and characterized nickel hydroxide, nickel oxide, and 1:1 and 2:1 nickel phyllosilicate species present in Ni/HZSM-5 catalyst prepared by depositionprecipitation.

The DP method studies indicate that there are many interesting and favorable catalyst properties that can be obtained from using the DP method versus the incipient wetness 
impregnation (IWI) technique. Of specific interest is the formation of nickel species with strong nickel-support interaction. This strong interaction allows for the formation of smaller, highly dispersed nickel particles, which is important for selective hydrogenolysis/HDO activity, and promotes higher stability due to resistance to sintering [6,7].

Another result of using the DP method to synthesize Ni/HZSM-5 catalyst is the formation of nickel metal particles on the exterior surface of the support, while leaving the acid sites within the pore structure intact. This could lead to a multifunctional catalyst system where large lignin molecules can be attacked by the nickel catalyst on the surface of the zeolite, and then the smaller fragments can diffuse into the zeolite pore structure where they are subjected to acid catalysis and the physical constraints of the HZSM-5 pore.

In this study, the effect of increasing the nickel loading in Ni/HZSM-5 on catalyst properties was observed. An optimal nickel loading for the DP method which would have the highest nickel loading while maintaining high dispersion and small particle size was determined. The change in the nickel loading was achieved through varying the concentration of nickel nitrate in the DP method, instead of varying the DP time. By keeping the DP method parameters constant except for nickel concentration, changes in the incorporation of nickel onto the zeolite support were observed. For the varying nickel loading experiments, a DP time of $5 \mathrm{~h}$ and a calcination temperature of $873 \mathrm{~K}$ were used.

Although these observations are related to those in the literature [5,6,11], there has not been in depth discussion about the effect of varying nickel precursor concentration using a nonexcess amount of nickel precursor and relatively long DP time. The changes in catalyst properties and characteristics and nickel site could affect the activity of the catalyst. Determining a highly effective nickel loading for the DP method was important for future work involving Ni/HZSM-5 catalyst. Using this loading, the effects of additional preparation parameters including DP time and calcination temperature were evaluated.

\section{Experimental}

\subsection{Catalyst Preparation}

The bi-functional catalysts, Ni/HZSM-5, were synthesized using a DP method similar to that of Burattin et al. [5,6]. For each catalyst preparation, $5 \mathrm{~g}$ of catalyst was synthesized with varying nickel loading, 5, 10, 12.5, 15, and $20 \mathrm{wt} \%$ nickel. All catalysts will be referred to by their nominal loading (based on the initial mass of nickel introduced during synthesis). DP method parameters, including concentration of $\mathrm{NH}_{4}-\mathrm{ZSM}-5$ support (Zeolyst International, CBV 2314), urea, nitric acid, temperature, stirring, and DP time, were kept constant. Unlike the standard method, which uses excess amounts of nickel nitrate and varies the DP time to control the nickel loading, the initial nickel nitrate concentration was used to control the nickel loading, and then a constant, and excess, DP time was used to incorporate the nickel. The following concentrations were used to synthesize the catalyst samples: $7.9 \mathrm{~g} \cdot \mathrm{L}^{-1} \mathrm{NH}_{4}-\mathrm{ZSM}-5,0.42 \mathrm{~mol} \cdot \mathrm{L}^{-1}$ urea, $0.02 \mathrm{~mol} \cdot \mathrm{L}^{-1}$ nitric acid, and $0.01-0.03 \mathrm{~mol} \cdot \mathrm{L}^{-1} \mathrm{Ni}\left(\mathrm{NO}_{3}\right)_{2} \cdot 6 \mathrm{H}_{2} \mathrm{O}$. All concentrations are based on the total amount of water, which depends on the required amount of support to make 5 $\mathrm{g}$ of catalyst of a specific nickel loading.

First, the nickel nitrate solution of the desired concentration is prepared. The nickel nitrate solution is then split into $4 / 5$ and $1 / 5$ portions. $\mathrm{NH}_{4}-\mathrm{ZSM}-5$ support is added to the $4 / 5$ portion and the resulting slurry is heated to $343 \mathrm{~K}$ under agitation. Urea and nitric acid are added 
to the $1 / 5$ portion of nickel nitrate solution, and this new solution is slowly added dropwise to the slurry heated at $343 \mathrm{~K}$. Once all the material is combined, the slurry is heated to $363 \mathrm{~K}$ and held at temperature for 5 or $16 \mathrm{~h}$ (DP time $=5$ or $16 \mathrm{~h}$ ) with $300 \mathrm{rpm}$ stirring. After the desired DP time, the slurry is removed from heat and quenched in an ice bath. The slurry is vacuum filtered and the remaining solid is washed with deionized water. The solids were transferred to a watch glass and dried overnight in an oven at $383 \mathrm{~K}$. The dried precursor was ground into a powder with a mortar and pestle, and stored.

The DP method is capable of forming a combination of nickel hydroxide and 1:1 nickel phyllosilicate species on the support [5,6,11]. During calcination, the nickel hydroxide decomposes into $\mathrm{NiO}$, and the 1:1 nickel phyllosilicate is transformed into 2:1 nickel phyllosilicate. He et al. [8] related the turnover frequency (rate of reactant conversion per catalyst site per time, TOF) of 2-phenylethyl phenyl ether by $\mathrm{Ni} / \mathrm{SiO}_{2}$ catalyst to calcination temperature and particle size; while the particle size increased with calcination temperature (673$1073 \mathrm{~K}$ ), the TOF reached a maximum with a calcination temperature around $973 \mathrm{~K}$. While the drop off in TOF from 973-1073 K calcination temperature may be due to the sintering of nickel (much larger particles were observed at calcination temperature of $1073 \mathrm{~K}$ ), the increase in TOF from 673-973 K calcination temperature may be attributed to a more complete transformation of a nickel-support species during calcination, followed by a greater extent of reduction to nickel metal prior to the reaction. For this reason, all catalyst precursors in this study were calcined either at $673 \mathrm{~K}$ or $873 \mathrm{~K}$. For the calcination, $2 \mathrm{~g}$ of catalyst precursor was calcined in air for $4 \mathrm{~h}$, applying a heating ramp of $10 \mathrm{~K} \cdot \mathrm{min}^{-1}$. After calcination, the sample was cooled and then stored for activation.

Calcined catalyst samples were then reduced in $\mathrm{H}_{2}$ gas environment. Approximately 0.45 $\mathrm{g}$ of calcined catalyst was placed in a quartz reactor tube connected to a flow system. The tube was first purged with $\mathrm{N}_{2}$ at $50 \mathrm{~mL} \cdot \mathrm{min}^{-1}$ for $10 \mathrm{~min} . \mathrm{H}_{2}$ gas was then flown into the reactor at 50 $\mathrm{mL} \cdot \mathrm{min}^{-1}$ for $5 \mathrm{~min}$, and then the reduction oven program was initiated. The catalyst was reduced at $733 \mathrm{~K}$ for $4 \mathrm{~h}$ with a $10 \mathrm{~K} \cdot \mathrm{min}^{-1}$ ramp. After reduction, the reactor tube was purged with $\mathrm{N}_{2}$ gas flow at $50 \mathrm{~mL} \cdot \mathrm{min}^{-1}$ and allowed to cool to room temperature.

Due to the design of a batch reaction system, the Ni/HZSM-5 catalyst would have to be exposed to air during loading of the reaction vessel, which would cause re-oxidation of the nickel metal. To prevent extensive re-oxidation and allow for a systematic and consistent oxygen exposure for all catalyst samples, a passivation procedure was used to form an oxidized surface layer on the nickel metal, which could then be reduced again in the reactor vessel in-situ under the reaction conditions.

After the reduction stage, the catalyst in the reactor was cooled to room temperature in a $\mathrm{N}_{2}$ environment by placing the reactor tube in an isopropanol and liquid $\mathrm{N}_{2}$ bath, and then a 5\% $\mathrm{O}_{2} / \mathrm{N}_{2}$ gas mixture was flown over the catalyst at $10 \mathrm{~mL} \cdot \mathrm{min}^{-1}$ for $1 \mathrm{~h}$. The reactor tube was then removed from the cold bath, returned to room temperature, and the $5 \% \mathrm{O}_{2} / \mathrm{N}_{2}$ gas mixture was flown over the catalyst at $10 \mathrm{~mL} \cdot \mathrm{min}^{-1}$ for an additional $1 \mathrm{~h}$. After passivation, the catalyst was removed from the apparatus and stored in a desiccator at room temperature for future reactions and catalyst characterization.

\subsection{Catalyst Characterization}

Textural properties of the catalyst samples were characterized with a MicromeriticsTriStar II 3020 BET surface analyzer. The specific surface area was determined by the 
Brunauer-Emmett-Teller (BET) model, the total pore volume was determined from nitrogen adsorption at a relative pressure of 0.99, the micropore volume was calculated from the DubininRadushkevich model, the mesopore volume was the difference between total and micropore volumes, and the mesoporous size distribution was calculated using the Barrett-Joyner-Halenda (BJH) model. These calculations were based on $\mathrm{N}_{2}$ adsorption-desorption isotherms at $77 \mathrm{~K}$. The micropore size distribution was obtained using the density functional theory (DFT) model from $\mathrm{CO}_{2}$ adsorption isotherms at $273 \mathrm{~K}$. Catalyst samples were either only calcined or calcined, reduced, and passivated, followed by degassing at $473 \mathrm{~K}$ for $2 \mathrm{~h}$ prior to characterization.

Inductively coupled plasma-optical emission spectrometer (ICP-OES) analysis was performed with a Perkin Elmer Optima 7000DV to determine the Si/Al of the HZSM-5 support in the active protonated form. Prior to ICP analysis, samples were digested using a CEM Mars 240/50 Microwave with "EasyPrep" vessels. For the digestion, $0.050 \mathrm{~g}$ of sample was weighed and $2 \mathrm{~mL}$ of $30 \% \mathrm{H}_{2} \mathrm{O}_{2}, 3 \mathrm{~mL}$ of $65 \% \mathrm{HNO}_{3}$, and $1 \mathrm{~mL}$ of $40 \% \mathrm{HF}$ was added to each sample and then sealed and microwave digested at $800 \mathrm{~W}(100 \%$, ramp for $25 \mathrm{~min}$ to $463 \mathrm{~K}$, and held for $20 \mathrm{~min}$ at $5.52 \mathrm{MPa})$. To neutralize the sample, $10 \mathrm{~mL}$ of $4 \% \mathrm{~B}(\mathrm{OH})_{3}$ was added and then placed in the microwave again at $800 \mathrm{~W}(100 \%$, ramp for $25 \mathrm{~min}$ to $423 \mathrm{~K}$, and held for $15 \mathrm{~min}$ at $1.03 \mathrm{MPa}$ ). Each sample was transferred using $50 \mathrm{~mL}$ of deionized water. For the ICP-OES analysis, the digested samples were diluted $10 \mathrm{x}$ with deionized water and ran against a multicalibration curve for $\mathrm{Si}, \mathrm{Al}$ and $\mathrm{Ni}$. The analysis utilized a Cámara Spray chamber and Cross-flow Gem Tip Nebulizer. The following conditions were used: Argon plasma flow of 15 $\mathrm{L} \cdot \mathrm{min}^{-1}$, auxiliary gas flow of $0.2 \mathrm{~L} \cdot \mathrm{min}^{-1}$, nebulizer gas flow of $0.8 \mathrm{~L} \cdot \mathrm{min}^{-1}, 1300 \mathrm{~W}$ power, and a peristaltic pump rate of $1.5 \mathrm{~mL} \cdot \mathrm{min}^{-1}$.

Temperature programmed reduction (TPR) analysis was used to calculate the $\mathrm{H}_{2} / \mathrm{Ni}$ uptake of Ni/HZSM-5 catalysts over increasing temperature was carried out using a quartz cell equipped with a thermal conductivity detector (TCD). A $5 \% \mathrm{H}_{2} / \mathrm{Ar}$ gas mixture was flown over the catalyst sample at $50 \mathrm{~cm}^{3} \cdot \mathrm{min}^{-1}$, and the temperature was ramped at $10 \mathrm{~K} \cdot \mathrm{min}^{-1}$ from room temperature to $1273 \mathrm{~K}$. All catalysts were calcined and further dried overnight at $383 \mathrm{~K}$ prior to TPR analysis. Enough catalyst to contain approximately $1.5 \mathrm{mg}$ of nickel was used for each TPR experiment. To confirm complete reduction of the nickel catalysts during the TPR experiments, the $\mathrm{H} / \mathrm{Ni}$ uptake was calculated from the integration of the TPR peaks (mmol of $\mathrm{H}_{2}$ consumed) and the nickel loading (mmol of nickel).

The types of nickel species present in the Ni/HZSM-5 were determined using x-ray diffraction (XRD). All diffractograms were obtained with a Rigaku diffractometer using nickelfiltered $\mathrm{CuK} \alpha$ radiation $(\lambda=0.15418 \mathrm{~nm})$. Catalysts after only calcination and after calcination, reduction, and passivation were characterized with XRD. The Scherrer equation, shown in equation (1), where $D_{p}$ is particle diameter $(\AA), \lambda$ is $C u K \alpha$ radiation wavelength $(\AA), \beta_{1 / 2}$ is the full width at half maximum (radians), and $\theta$ (Bragg angle) is the position ( $1 / 2$ value of $2 \theta$ position) (radians), was used to approximate the particle size of the nickel. Such an approximation has been used with Ni/HZSM-5 catalyst; however, this may not be the most accurate approximation of nickel particle size due to the presence of HZSM-5 peaks which need to be decoupled from the nickel peak [10]. This approximation is more easily calculated using a more amorphous support such as silica, where the amorphous silica peak does not interfere with the prominent nickel peak.

$$
D_{p}=\frac{0.94 \lambda}{\beta_{1 / 2} \cos \theta}
$$


All transmission electron microscopy (TEM) images were obtained using a JEOL Model JEM-1200 EXII System. Only catalysts that were calcined, reduced and passivated were observed. Samples were prepared using a methanol dispersion method and placed on a copper grid. Particle sizes were determined from micrographs using Image Tool 3.0 software. The mean particle sizes and distributions were determined from the measurement of over 300 particles for each catalyst (Supplementary Material Fig. S1 and S3).

Available nickel sites, dispersion (\%), and approximate nickel particle size were determined using a Micromeritics ASAP 2020 with a $\mathrm{H}_{2}$-chemisorption unit. All catalyst samples were calcined prior to analysis. An in-situ reduction was performed with $\mathrm{H}_{2}$ gas (99.9999\% purity), at $733 \mathrm{~K}$ for $4 \mathrm{~h}$ using a $10 \mathrm{~K} \cdot \mathrm{min}^{-1}$ ramp. The samples were then outgassed 1 $\mathrm{h}$ at $733 \mathrm{~K}$ and $3 \mathrm{~h}$ at $308 \mathrm{~K}$. The $\mathrm{H}_{2}$-chemisorption was carried out at $308 \mathrm{~K}$. H/Ni uptake was based on a 1:1 stoichiometry. The amount of chemisorbed $\mathrm{H}_{2}$ was calculated from the difference between total $\mathrm{H}_{2}$ uptake and physisorption $\mathrm{H}_{2}$. The dispersion was calculated using the following calculation:

$$
D(\%)=100 * \frac{H \text { atoms }(\mathrm{mmol})}{\mathrm{Ni}(\mathrm{mmol})}
$$

In this calculation, $D$ is the dispersion in $\%, H$ atoms is the amount of hydrogen atoms in mmol based on the volume of $\mathrm{H}_{2}$ chemisorbed, and $\mathrm{Ni}$ is the amount of nickel in mmol based on the nickel loadings determined by ICP-OES. The estimate particle size was calculated using the following approximation [15]:

$$
d_{p}=\frac{101}{D(\%)}
$$

In this approximation $d_{p}$ is particle diameter in $\mathrm{nm}$ and $D$ is the dispersion in $\%$. This analysis is based on the assumption that a spherical particle that is less than $1 \mathrm{~nm}$ in diameter exhibits $100 \%$ dispersion [15].

The acid strength of the support with and without nickel metal was measured using a potentiometric titration method [16]. A catalyst sample and acetonitrile suspension was titrated with n-butylamine, and the potential was measured with a $\mathrm{Ag} / \mathrm{AgCl}$ electrode. The method can determine the number of acid sites and allows for the calculation of acid site density $\left(\mathrm{mmol} \cdot \mathrm{m}^{-2}\right)$, as well as approximate the acid strength based on the potential $(\mathrm{mV})$. The potential relates to the acid strength using the scale that a strong acid has a potential greater than $100 \mathrm{mV}$, and a weak acid is less than $-100 \mathrm{mV}$.

X-ray photoelectron spectroscopy (XPS) was used to observe surface species of the supported nickel catalysts. The spectra were obtained on a VG Escalab 200R electron spectrometer, equipped with a hemispherical electron analyzer and $\mathrm{MgK \alpha}(\mathrm{hv}=1253.6 \mathrm{eV})$ photon source. Prior to the analysis, the catalysts samples, which have been calcined, reduced, and passivated, using the procedure mentioned above, were re-reduced in-situ with $\mathrm{H}_{2}$ gas at 733 $\mathrm{K}$ for $1 \mathrm{~h}$. After reduction, samples were degassed for 15 min under $1 \times 10^{-4} \mathrm{~Pa}$ with the residual pressure being $\mathrm{H}_{2}$ gas. Due to pretreatment chamber of the XPS not being able to maintain high vacuum, some air diffuses into the chamber and oxidizes the surface of the reduced catalyst samples prior to XPS analysis. The surface oxidized catalyst samples used for XPS analysis are a good representation of the catalysts that will be used for future reactions because prior to reaction the catalysts are reduced and passivated; therefore, since there is no additional reduction 
prior to reaction, the starting catalyst will have an oxidized surface similar to what occurs in the pretreatment chamber prior to XPS analysis. The binding energies were referenced to the $\mathrm{Si} 2 \mathrm{p}$ level of the HZSM-5 support at $103.2 \mathrm{eV}$. Intensities of the peaks were calculated from the respective peak areas after background subtraction and spectrum fitting by a combination of Gaussian/Lorentzian functions. The relative surface atomic ratios were determined from the corresponding peak intensities, corrected with tabulated sensitivity factors, with a precision of $\pm 7 \%$.

\section{Results and Discussion}

\subsection{Catalyst with Varying Nickel Loading}

\subsubsection{Textural Properties}

The textural properties obtained for catalysts with varying nickel loading from 5-20 wt\% after calcination, and after calcination, reduction, and passivation are presented in Table 1. As expected, the BET surface area decreases significantly when loading the HZSM-5 support with nickel. For the calcined samples, the surface area is similar for all samples except for the $20 \mathrm{wt} \%$ sample, which is approximately $50 \mathrm{~m}^{2} \cdot \mathrm{g}^{-1}$ lower due to the large amount of nickel present. For the calcined, reduced, and passivated catalysts, some surface areas are reduced, and an optimal surface area of $325 \mathrm{~m}^{2} \cdot \mathrm{g}^{-1}$ was reached at moderate nickel loading, $12.2 \mathrm{wt} \%$. This is possibly due to the formation of slightly larger nickel particles caused by sintering, but generally the surface areas remained in the $250-325 \mathrm{~m}^{2} \cdot \mathrm{g}^{-1}$ range.

As expected, the HZSM-5 support exhibits the largest micropore volume (Table 1). There is a decrease in the pore volume of HZSM-5 when nickel metal is loaded on the support. For calcined samples the micropore volume slightly decreases with nickel loading, while mesopore volume increases; thus indicating that micropores are being blocked by the nickel particles, and that the nickel species present after calcination lead to the formation of additional mesopores. This phenomenon was described by Chen et al. who related the presence of defects in the HZSM-5 with the formation of nickel phyllosilicates and attributed the development of mesopores to the aggregation of these defects [14]. After reduction, $\mathrm{Ni}^{2+}$ species are reduced to $\mathrm{Ni}$ metal and the trends are no longer evident. While the change in pore/micropore volume is not very large between catalyst samples, it is worth noting a decrease in micropore volume after incorporation of nickel to the support.

The shift from microporous to mesoporous volume is consistent with trends observed for the BET isotherms, BJH desorption pore distribution, and $\mathrm{CO}_{2}$ DFT porosity distributions. Fig. 1 shows the BET isotherms for both calcined catalyst samples and calcined, reduced, and passivated catalyst samples. All the samples exhibit a type I isotherm according to IUPAC classifications, which is characteristic of microporous solids. However, the shape of the hysteresis loop changes with the nickel loading [17]. The HZSM-5 isotherm exhibits an H4 hysteresis loop, which is characteristic of a microporous structure with some mesoporosity between the zeolite particles. As the nickel loading increases, the hysteresis loop becomes narrower, and the shape shifts toward a H3 type hysteresis loop. This suggests the presence of aggregates that have plate-like structures with slit pores in the mesopore range [17]. This shift to H3 hysteresis was observed in Nares et al. [11]. It was attributed to the formation of nickel species with a lamellar structure, possibly 1:1 nickel phyllosilicate and nickel hydroxide species. 
All the samples have been calcined at $873 \mathrm{~K}$, so all the nickel hydroxide should be decomposed into $\mathrm{NiO}$. The presence of the $\mathrm{H} 3$ hysteresis loop indicates that lamellar nickel-support species (such as 2:1 nickel phyllosilicate) are present after calcination. As can be seen between the calcined only samples and the reduced samples, the H3 hysteresis loop becomes narrower after reduction, indicating the loss of mesoporosity, which is corroborated by the decrease in mesoporous volume between calcined and reduced catalysts presented in Table 1. This can be attributed to the loss of the lamellar structure of nickel-support species when $\mathrm{Ni}^{2+}$ is reduced to nickel metal.

The BJH pore distribution shown in Fig. 2 exhibits a shift from mesopores with a specific diameter of $4 \mathrm{~nm}$ to a larger sized mesopore with a wider distribution of sizes with increasing nickel loading. From the Fig. 2a (calcined samples) and Fig. 2b (reduced samples), again the shift from high to low mesoporosity is observed (loss of the large broad peak present in Fig. 2a) which indicates a change from nickel-support lamellar species to nickel metal particles after reduction.

The DFT pore distribution in Fig. 3 shows that the catalysts have two main micropore sizes, one being $0.58 \mathrm{~nm}$, and the other being $0.49 \mathrm{~nm}$. This is consistent with HZSM-5 support's average pore size around $0.55 \mathrm{~nm}$, where the $0.58 \mathrm{~nm}$ pores represent the main channels, while the $0.49 \mathrm{~nm}$ pores represent the narrower side channels of the zeolite. Fig. 3 also shows a decrease in the number of micropores with increasing nickel loading. The fact that there is a decrease in the peak height and not a shift in the distribution indicates that the nickel particles are fully blocking micropores instead of partial blocking on the mouth of the pores. In addition, only the peak at $0.58 \mathrm{~nm}$ appears to decrease with low nickel loadings, while at higher nickel loadings both micropores start to decrease; this suggests that the larger main pore is preferred for nickel deposition, while the nickel is only deposited on the side channels in significant amounts when the nickel loading is greater than $10 \mathrm{wt} \%$.

\subsubsection{Active Site Properties}

\subsubsection{Nature of Nickel Species}

The presence of nickel species on the support was confirmed with x-ray diffraction (XRD). The XRD patterns for calcined Ni(x)/HZSM-5 catalysts and calcined, reduced, and passivated $\mathrm{Ni}(\mathrm{x}) / \mathrm{HZSM}-5$ catalysts are shown in Fig. 4. The three diffraction peaks at $2 \theta$ equal to $37.25^{\circ}, 43.28^{\circ}$, and $62.87^{\circ}$ (Fig. 4a) confirm the presence of $\mathrm{NiO}$ [18-20]. At low nickel loading, the $\mathrm{NiO}$ peaks are very small and are mostly indistinguishable from the HZSM-5 peaks. However, for the higher nickel loading, the NiO peaks are more intense. On the other hand, Fig. 4b only shows two diffraction peaks at $44.49^{\circ}$ and $51.84^{\circ}$, and they correspond to Ni [21-23]. The presence of the nickel indicates that the $\mathrm{NiO}$ was reduced during reduction and that the passivation technique prevented extensive re-oxidation of the nickel particles. Similar to the calcined samples, the peak intensity of the nickel increased with nickel loading. For both calcined, and calcined, reduced, and passivated catalysts, the increase in peak intensity with nickel loading indicates that the amount of nickel present on the support was increased. From the XRD results, the catalysts were confirmed to have nickel metal after calcination, reduction, and passivation of the catalysts, and will therefore have active nickel present for future reactions. The calculated particle sizes from the Scherrer equation based on the XRD results are presented in Table 2. 
TPR temperature profiles for all the calcined catalyst samples are shown with increasing nickel loading in Fig. 5. Nickel typically reduces from $\mathrm{Ni}^{2+}$ to $\mathrm{Ni}^{0}$ in one step; therefore, the presence of three different peaks suggests that there are $\mathrm{Ni}^{2+}$ species with different local environments, whether it could be $\mathrm{NiO}$ or nickel-support species. The first and lowest temperature peak around $648 \mathrm{~K}$ is the main peak, and is observed for all catalyst samples. This lower temperature peak is indicative of $\mathrm{NiO}$, and the $\mathrm{H}_{2}$ uptake at this temperature increases with nickel loading, suggesting that an increasing amount of the nickel present is transformed into $\mathrm{NiO}$ after calcination, and is more easily reduced during the TPR experiment. It is worth noting a slight shift of the peak toward lower temperatures as the nickel loading is increased, with the most significant deviation obtained for the $20 \mathrm{wt} \%$ nickel catalyst. This observation suggests that larger $\mathrm{NiO}$ particles are present and interact with each other instead of interacting with the support, making it easier to reduce these particles.

The two broader peaks located at higher temperatures (around $773 \mathrm{~K}$ and $873 \mathrm{~K}$ ) are attributed to $2: 1$ nickel phyllosilicate species, which are $\mathrm{Ni}^{2+}$ species that have formed strong nickel-support interactions with the aluminosilicate structure, and are unable to be decomposed into $\mathrm{NiO}$ during calcination $[5,6,11]$. As a result, a higher temperature is required to reduce these nickel-support species. As shown in Fig. 5, as the nickel loading increases, the amount of nickel in the 2:1 nickel phyllosilicate form decreases, while the amount in the NiO form becomes more prevalent after calcination. As mentioned in section 3.1, this mixture of nickel species is expected from the DP method. Overall, we observed the one $\mathrm{NiO}$ peak along with the $2: 1 \mathrm{Ni}$ phyllosilicate peaks/shoulder at the higher temperature. From the TPR results, the Ni/HZSM-5 samples are shown to have a mixture of nickel species present after calcination, reduction, and passivation, and in addition, all catalysts exhibited an $\mathrm{H} / \mathrm{Ni}$ uptake of approximately 2, suggesting complete reduction of the nickel catalyst.

When compared to the results of Burattin et al. [5], for a DP time of $5 \mathrm{~h}$ for $20 \mathrm{wt} \%$ nickel, there is most likely the formation of both nickel hydroxide and 1:1 nickel phyllosilicate species, since there is not much excess DP time for this concentration of nickel nitrate, resulting in easier to reduce nickel species along with $\mathrm{H}_{2}$ spillover effects [24]. However, as the nickel nitrate concentration is decreased, the DP time of $5 \mathrm{~h}$ becomes increasingly excessive, resulting in the formation of more 1:1 nickel phyllosilicate. This trend agrees with the observation from Burattin et al. [5], of a shift from a mixture of nickel hydroxide and 1:1 nickel phyllosilicate to solely phyllosilicate species as the DP time increased, thus explaining the presence of larger shoulder peaks for the $5 \mathrm{wt} \%$ sample compared with the $\mathrm{NiO}$ peak.

An important point to be made from these TPR profiles is that all the TPR peaks have relatively low temperatures. This is indicative of nickel species being present on the exterior surface of the HZSM-5, and not located within the pore structure [25]. This is consistent with the TEM, XRD, and $\mathrm{H}_{2}$-chemisorption results in Table 2, which show that the nickel particles are much larger than the narrow pore size of the zeolite, and therefore must be located on the exterior surface.

\subsubsection{Particle Size and Dispersion}

TEM, XRD, and $\mathrm{H}_{2}$-chemisorption have been utilized to characterize the size and dispersion of the nickel particles (Table 2). TEM mean particle sizes and distributions along with the TEM images for the catalysts with varying nickel loading can be seen in supplementary material Fig. S1. As mentioned previously, the nickel particle size approximations from $\mathrm{H}_{2}-$ 
chemisorption were based on the dispersions (Eq. 3) and the particle size approximations from XRD results were calculated using the Scherrer equation (Eq. 1). As can be seen from the $\mathrm{H}_{2^{-}}$ chemisorption data, the dispersion and therefore the particle size of the nickel were similar for catalysts with nickel loading of 5-15 wt \%; however, a large drop in dispersion and an increase in particle size (presumably due to sintering) was found for the $20 \mathrm{wt} \%$ nickel catalyst, which is in agreement with the slight shift observed for the $20 \mathrm{wt} \%$ TPR profile. The particle sizes determined from TEM and XRD all tend to be smaller than the sizes approximated from $\mathrm{H}_{2}-$ chemisorption. This difference between measurements was also observed in the particle sizes reported by Song et al. [10] where nickel metal was supported on HZSM-5 with a similar $\mathrm{SiO}_{2} / \mathrm{Al}_{2} \mathrm{O}_{3}$ ratio to the HZSM-5 used in this study. Although the authors reported similar TEM and XRD measurements of the particle size (11 nm and $14 \mathrm{~nm}$, respectively), the dispersion of $3.6 \%$ would give an approximate particle size of about $28 \mathrm{~nm}$, using equation (1) [10].

TEM measurements are generally representative of particles that can be viewed on the edges of the catalyst support. Since the support centers are very dark regions preventing all the particles from being measured, TEM measurements alone may be misleading. On the contrary, both XRD and $\mathrm{H}_{2}$-chemisorption approximations provide an overall measure of a sample's particle size instead of observing individual particles. Since the TEM and XRD are in close agreement, (a specific and an average measuring technique) the catalyst particles should be taken to be the actual particle size of the nickel particles (in the $10 \mathrm{~nm}$ range).

Two discrepancies that need to be addressed are the much larger XRD particle size approximation for the $5 \mathrm{wt} \%$ catalyst, and the lack of agreement between the dispersion, TEM, and XRD measurements for the $20 \mathrm{wt} \%$ sample (Table 2). As shown by the $\mathrm{H}_{2}$-chemisorption dispersion measurements and TEM, the 5-15 wt\% catalyst nickel particles appear to be the same size; however, the XRD for the $5 \mathrm{wt} \%$ deviates from this trend. The TEM particle measurements for the $5 \mathrm{wt} \%$ sample were slightly larger than the 10-15 wt\% catalysts, but not to the extent determined by the Scherrer equation from XRD. The XRD peak for the nickel in the 5 wt\% catalyst is barely distinguishable from the support peaks (Fig. 4b). As a result, the peak fit is much narrower than the actual nickel peak. This would cause the Scherrer equation approximation to overestimate the particle size $\left(D_{p}\right.$ increases with decrease in $\left.\beta_{1 / 2}\right)$.

This inability to obtain an accurate peak fit also occurred for the $20 \mathrm{wt} \%$ catalyst. In this case, the nickel peak was so intense that the support peaks are obscured and the peak fit for nickel is much broader than the actual nickel peak. This causes the size approximation to be smaller than expected. The TEM measurement for the $20 \mathrm{wt} \%$ sample is also smaller than expected due to the fact that larger nickel loadings on the support lead to darker regions covering more of the catalyst samples. This allows only counting of particles on the edges of the catalyst support. Overall, the general trend of the dispersion and resulting size approximations are in agreement, in that the dispersions and approximate particle sizes are similar for catalysts with 5$15 \mathrm{wt} \%$. The particle sizes from the TEM and XRD measurements $(\sim 10 \mathrm{~nm})$ should be reported as the actual particle sizes. These dispersion values, which estimate particle sizes much larger than the actual particle sizes, are consistent with what is reported in the literature [10].

\subsubsection{Acid Strength}

Characterization of the acid sites on the HZSM-5 support is presented in Table 3. The acid strength and site density of the nickel catalysts are compared to the support without nickel. The acid strength can be determined according to the criterion proposed by Cid and Pecchi [16]: 
$\mathrm{E}_{0}>100 \mathrm{mV}$, very strong acid sites; $0<\mathrm{E}_{0}<100 \mathrm{mV}$, strong acid sites; $-100<\mathrm{E}_{0}<0 \mathrm{mV}$, weak acid sites; $\mathrm{E}_{0}<-100 \mathrm{mV}$, very weak acid sites. As seen from the potentiometric titration data, the support without nickel has high acid strength (represented by a potential greater than $100 \mathrm{mV}$ ) as expected for HZSM-5 due to the presence of Brønsted acid sites. However, after incorporation of nickel and calcination, the strong acidity is lost (less than $100 \mathrm{mV}$ ). This suggests that the protonated Brønsted acid sites could have been lost (1) due to the $\mathrm{H}^{+}$counter-ions being replaced by $\mathrm{Ni}^{2+}$ counter-ions, forming weak Lewis acid sites and/or (2) due to the blockage of pores by the formation of lamellar $\mathrm{Ni}^{2+}$ species on the support surface. After reduction and passivation, some of the acidity returns and the catalysts have an overall moderate to strong acidity. These results suggest that as $\mathrm{Ni}^{2+}$ species are reduced and form small particles, some Brønsted acid sites are recovered, thereby increasing acid strength.

The increase in acid strength with increasing nickel loading (Table 3) can be ascribed to the introduction of more Lewis acid sites on the support due to the increase of $\mathrm{Ni}^{2+}$ loaded on the support, since the nickel cations can act as electron-acceptors [14]. The significant increase in acid strength from the calcined catalysts to the reduced and passivated catalysts can be attributed to a combination of factors. The first being the recovery of acid sites during the reduction of $\mathrm{Ni}^{2+}$, which generates smaller nickel particles and allows the titrating probe molecule to access more acid sites; the second is during the passivation, the nickel surface sites become $\mathrm{Ni}^{2+}$ again which, as mentioned, act as Lewis acid sites. Due to these factors, the acidity of the reduced and passivated catalyst is higher than the calcined catalyst, but still lower than HZSM-5 alone. The acid site density remains similar for all catalyst samples (with an average value of 0.0048 $\left.\mathrm{mmol} \cdot \mathrm{m}^{-2}\right)$.

\subsubsection{Surface Nickel Species}

XPS analysis was performed on the Ni/HZSM-5 catalysts after calcination, reduction, passivation, and re-reduction in-situ $(1 \mathrm{~h})$. As mentioned in section 2.2 , the reduced catalyst samples are exposed to air during degassing of the sample prior to XPS analysis. The Ni $2 p$ core-level spectra are depicted in Fig. S2. XPS analysis of the Ni $2 p$ region in the catalysts revealed two partially overlapped $\mathrm{Ni} 2 \mathrm{p}$ doublets in addition to a satellite peak. The $\mathrm{Ni} 2 \mathrm{p}_{3 / 2}$ region corresponds to the doublet around $853 \mathrm{eV}$ and the $\mathrm{Ni} 2 \mathrm{p}_{1 / 2}$ region corresponds to the doublet around $870 \mathrm{eV}$. The binding energies (BEs) of the most intense Ni 2 $\mathrm{p}_{3 / 2}$ component of each catalyst, their relative proportion percentage, and the $\mathrm{Ni} / \mathrm{Si}$ atomic ratio are summarized in Table 4. The spectra displayed a peak at a BE of $852.2 \pm 0.2 \mathrm{eV}$ assigned to $\mathrm{Ni}^{0}$, together with another peak at a higher binding energy, $854.4 \pm 0.3 \mathrm{eV}$, corresponding to $\mathrm{NiO}$ species [26-30]. The peaks at around $870 \mathrm{eV}$ and $872 \mathrm{eV}$ in the $\mathrm{Ni} 2 \mathrm{p}_{1 / 2}$ region also correspond to $\mathrm{Ni}^{0}$ and $\mathrm{NiO}$ species, respectively. The low intensity peaks at about $858 \mathrm{eV}$ and $876 \mathrm{eV}$ are attributed to satellite peaks. The results show that there were no significant trends noted for the percentage of reduced nickel on the surface with nickel loading. It is important to note that the surface nickel is not fully reduced, and that the average extent of reduction is around $66 \pm 7 \%$. This incomplete surface reduction indicates that the catalysts were exposed to air within the pretreatment chamber leading to surface oxidization prior to XPS analysis.

As expected, the Ni/Si atomic ratio increased with nickel loading, following a linear trend (Fig. 6). The 10-15 wt\% samples are close to this linear relationship, which agrees with the fact that these three catalysts have similar particle sizes and dispersions, as shown by TEM, XRD, and $\mathrm{H}_{2}$-chemisorption. This suggests that the increase in $\mathrm{Ni} / \mathrm{Si}$ atomic ratio is solely due to an 
increase in nickel loading. This comparison can be made since the percentage of reduced nickel on the surface for all these catalysts is similar. However, the $5 \mathrm{wt} \%$ and $20 \mathrm{wt} \%$ samples deviate from this linear relationship, which has some implications. The $5 \mathrm{wt} \%$ sample is below this linear trend, indicating that the $\mathrm{Ni} / \mathrm{Si}$ atomic ratio on the surface is smaller than expected. This indicates that the nickel has slightly lower dispersion with larger particles. This is in agreement with the TEM and XRD particle sizes observed.

The $20 \mathrm{wt} \%$ sample is above this linear trend, which would indicate that the dispersion of this catalyst is higher than the others. However, as seen from the chemisorption results, the dispersion is much lower than the other catalysts indicating that the particle size is larger. This deviation from the linear trend towards higher metal/support atomic ratio despite lower dispersions and larger particle sizes has been observed in various studies from the Escalona group using different supported metal catalysts with high metal loadings [31-34]. This discrepancy has been observed when there is high metal loading and high support surface coverage, because at this point the metal particles start to form larger aggregates covering up the smaller particles on the support. Typically for the small particles, the x-ray source is able to contact the support surface in between the particles, but when these larger aggregates in close proximity start to form over the support surface, the x-ray can no longer penetrate to the available support surface (reducing the $\mathrm{Si}$ in the Ni/Si atomic ratio). This inability to observe the support surface causes the Ni/Si ratio from XPS to increase even though the nickel metal in fact has lower dispersion and larger particle size.

\subsection{Catalysts with Varying Preparation Conditions}

The previous section indicated that the $15 \mathrm{wt} \%$ catalyst displayed the most promising characteristics with the highest nickel loading while maintaining a similar dispersion, and particle size compared to the lower loading catalysts. Having small particles size and high dispersion are characteristics of interest for hydrodeoxygenation. This preparation has therefore been selected to further study the effect of DP time (5 and $16 \mathrm{~h})$ and calcination temperature (673 vs. $873 \mathrm{~K}$ ) on the textural and chemical characteristics of new catalysts. The four different preparations will be referred according to the following abbreviation: DPX_CalY, where X is the number of hours 5 or 16 , and Y is the calcination temperature $673 \mathrm{~K}$ or $873 \mathrm{~K}$ (e.g., DP5_Cal873 is the preparation with a DP time of $5 \mathrm{~h}$ and calcined at $873 \mathrm{~K}$ ).

\subsubsection{Textural Properties}

Similar to section 3.1.1, the textural properties of the various preparations were characterized using BET isotherms, BJH desorption pore distribution, and $\mathrm{CO}_{2}$ DFT porosity distributions. According to the textural properties of $\mathrm{Ni}(15) / \mathrm{HZSM}-5$ catalysts obtained at different DP time and calcination temperature (Table 5), the expected and significant decrease in BET specific surface area between HZSM-5 support and Ni-loaded catalysts was confirmed. However, the surface area between all $15 \mathrm{wt} \%$ catalyst samples does not vary significantly, with the exception of the reduced and passivated catalyst obtained after long DP time and calcined at $673 \mathrm{~K}$, which has a much lower surface area.

The decrease in the micropore volume with loading of nickel onto the support is consistent with earlier findings (section 3.1.1) with the mechanism already invoked being: micropores are being blocked by the nickel particles, and the development of mesopores favored 
by the formation of lamellar $\mathrm{NiO}$ species. With an increase in DP time, there is an expected increase in the amount of strong nickel-support species (lamellar nickel phyllosilicate species) formed on the support, and thereby more mesopore volume. Furthermore, after reduction, all the catalysts exhibited a decrease in mesopore volume, indicating the removal of lamellar species due to the formation of nickel metal particles. However, the longer DP time catalysts still had greater mesopore volumes than the plain support. The short DP time catalysts lost all the additional mesopore volume suggesting that the lamellar nickel species were mostly changed to nickel particles for the short DP time. However, with the longer DP time, which was expected to have more 1:1 nickel phyllosilicate species, the lamellar species were not completely transformed even after calcination and reduction.

The trends observed in Table 5 are consistent with the BET isotherms, BJH desorption pore distribution, and $\mathrm{CO}_{2}$ DFT porosity distributions shown in Fig. 7, 8, and 9. The BET isotherms for the new preparations (Fig. 7) exhibit the same type I isotherms as described in section 3.1.1. Significantly larger hysteresis loops were observed when applying longer DP time; indicating an increase in the mesopore distribution. On the contrary, variations in calcination temperatures had limited impact. As mentioned previously (section 3.1.1), isotherms shift from an $\mathrm{H} 4$ to an $\mathrm{H} 3$ hysteresis loop, with the addition of nickel metal using DP. However, for the calcined only samples, the H3 loop becomes broader with DP time, which is in agreement with the fact that more 1:1 nickel phyllosilicate species are being formed with longer DP time. Samples with a calcination temperature of $673 \mathrm{~K}$ all had slightly wider hysteresis loops than the corresponding $873 \mathrm{~K}$ samples, and this agrees with the fact that fewer lamellar nickel species were transformed at the lower calcination temperature. When the samples are reduced, the H3 hysteresis loops become narrower, indicating the loss of mesoporosity. As mentioned previously (section 3.1.1), this can be attributed to the lamellar structure of the nickel species being lost when the $\mathrm{Ni}^{2+}$ is reduced to nickel metal.

The BJH pore distribution presented in Fig. 8 shows the presence of a mesopore with a specific diameter of $4 \mathrm{~nm}$, along with a broad distribution of larger mesopores. The 16h DP time catalysts have the largest peaks at $4 \mathrm{~nm}$ and also have an additional shoulder peak. For the calcined samples (Fig. 8a) with short DP time, the calcination temperature did not have a strong effect on the pore volume distribution. However, for the two $16 \mathrm{~h}$ DP time catalysts, the catalyst calcined at $873 \mathrm{~K}$ had a smaller $4 \mathrm{~nm}$ peak than the catalyst calcined at $673 \mathrm{~K}$. This may be attributed to further transformation of the lamellar nickel species at the higher calcination temperature. Comparing the calcined samples to the reduced and passivated samples (Fig. 8a vs. $\mathbf{8 b}$ ), the shift from high to low mesoporosity can be confirmed by the decrease in the large $4 \mathrm{~nm}$ peak and the loss of the broad peaks. This indicates a change from lamellar $\mathrm{Ni}^{2+}$ species to nickel metal particles after reduction. Broad peaks for the $16 \mathrm{~h}$ DP catalysts still remained after reduction indicating that some mesoporosity was maintained.

The DFT pore distribution (Fig. 9) shows that the catalysts have two main micropore sizes $(0.58$ and $0.49 \mathrm{~nm})$, which is consistent with the HZSM-5 average pore size of $0.55 \mathrm{~nm}$. As discussed in section 3.1.1, the decrease in the peak height instead of a shift in the distribution indicates full blocking of micropores instead of partial blocking on the mouth of the pores. A decrease in the number of micropores was observed with increasing calcination temperature. Specifically, the peak at $0.49 \mathrm{~nm}$ appears to decrease more significantly than the $0.58 \mathrm{~nm}$ pore with increase in calcination temperature. The $0.58 \mathrm{~nm}$ pore appears to decrease with the incorporation of nickel, while the varying preparation conditions had little effect. However, for the $0.49 \mathrm{~nm}$ pore, calcination had a significant effect even for the support without nickel. This 
suggests that even though some of the smaller side pores are blocked by the incorporation of nickel, the loss of this size pore is mostly attributable to using higher calcination temperatures, suggesting possible destruction or collapse of the mouth of these side channels. However, these effects may be isolated to the pore openings on the surface, since the XRD pattern does not indicate a significant change in the support structure; this will be discussed in greater detail in section 3.2.2.1.

Taken together, BET isotherms, $\mathrm{BJH}$ desorption pore distribution, and $\mathrm{CO}_{2}$ DFT porosity distributions suggest three conclusions: (1) the loading of nickel on the support causes the microporous structure to be blocked by nickel particles, (2) the presence of mesopores increases with the formation of lamellar $\mathrm{Ni}^{2+}$ species, and (3) after reduction, the extent of mesoporosity decreases as nickel particles are formed.

The DP16_Cal673 catalyst had a lower surface area after reduction, but it also had a lower micropore volume, compared to the other three catalysts. Unlike the first experiment, where catalyst loading was varied and the $20 \mathrm{wt} \%$ sample had a lower surface area and micropore volume due to the larger amount of nickel present on the support, in this second experiment all the catalysts have the same loading. The additional pore blockage and loss of surface area have to be attributed to something else not yet discussed. As will be discussed in section 3.2.2.2, this deviation by the DP16_Cal673 catalyst is related to the dispersion, which in the first set of experiments did not vary between the catalysts with varying loading, except after overloading at $20 \mathrm{wt} \%$ (Table 2). However, for this second set of experiments with varying preparation conditions, the dispersion did vary between catalysts.

\subsubsection{Active Site Properties}

\subsubsection{Nature of Nickel Species}

The presence of nickel species on the support was confirmed with XRD. The XRD patterns for various preparations of $\mathrm{Ni}(15) / \mathrm{HZSM}-5$ are shown in Fig. 10. The three diffraction peaks at $2 \theta$ equal to $37.25^{\circ} ; 43.28^{\circ}$ and $62.87^{\circ}$ (Fig. 10a) confirm the presence of $\mathrm{NiO}$ [18-20]. At this nickel loading, the $\mathrm{NiO}$ peaks are very small and are mostly indistinguishable from the HZSM-5 peaks. Alternatively, Fig. 10b only shows two diffraction peaks at $44.49^{\circ}$ and $51.84^{\circ}$ corresponding to $\mathrm{Ni}$ [21-23]. The presence of the nickel species indicates that the passivation technique used prevented extensive re-oxidation of the nickel particles. Similar to the NiO peaks, the nickel peak intensities did not vary significantly with the preparation conditions. In addition, no significant destruction/loss of crystallinity of the support was observed from the support peaks. From the XRD results, these catalysts were confirmed to have nickel metal after calcination, reduction, and passivation of the catalysts.

TPR temperature profiles for all the calcined catalyst samples are shown in Fig. 11. Similar to the varying nickel loading study, the TPR profiles exhibit multiple peaks which, as mentioned previously (section 3.1.2.1), suggests that there are different forms of $\mathrm{Ni}^{2+}$ on the support. However, with varying preparation conditions some new phenomena were observed. When calcination temperature is constant and DP time is varied, there is only a slight deviation in the shape of the TPR peaks (Fig. 11). However, when the calcination temperature is varied, there is a shift in the TPR peaks as well as a change in shape. The TPR peaks for the catalysts calcined at $873 \mathrm{~K}$ (Fig. 11) are quite similar to the peaks seen in Fig. 5 (for 10-20 wt\% Ni samples) with the $\mathrm{NiO}$ peak around $648 \mathrm{~K}$ and the shoulder around $773 \mathrm{~K}$ attributed to the 
presence of NiO-support species, regardless of DP time. The DP16_Cal873 catalyst having a broader peak with a larger shoulder than the DP5_Cal873 catalyst (Fig. 11) is consistent with the mixture of the nickel species changing from predominantly nickel hydroxide to predominantly 1:1 nickel phyllosilicate with increasing DP time.

When a lower calcination temperature is used, the TPR peak shapes look quite different (Fig. 11). There are two main factors for this difference. The first involves the lower calcination temperature not being able to transform the 1:1 nickel phyllosilicate into 2:1 nickel phyllosilicate. For this reason, the shoulder resembles a peak instead of a broad shoulder. The second factor deals with a phenomenon observed for supported $\mathrm{Ni}$, and even specifically for $\mathrm{Ni} / \mathrm{HZSM}-5$, which entails temperature shifts that are associated with changes in calcination temperature [35,36]. Reports in the literature indicate that with increasing calcination temperature, the TPR peaks shift to higher temperatures. This is attributed to not a change in the nickel species present, but simply to the notion that the same nickel species develop stronger interactions with the support material [35,36]. Zhang et al. [36] observed approximately $100 \mathrm{~K}$ shifts in the TPR peaks between Ni/HZSM-5 calcined at $673 \mathrm{~K}$ and $873 \mathrm{~K}$. For this reason, it is likely that the TPR peaks for the samples calcined at $673 \mathrm{~K}$ (Fig. 11) exhibit the same two TPR peaks as the catalysts calcined at $873 \mathrm{~K}$, but the peaks are just shifted to a slightly lower temperature $(623 \mathrm{~K}$ and $698 \mathrm{~K}$, instead of $648 \mathrm{~K}$ and $773 \mathrm{~K}$, respectively) due to a less strong interaction between the nickel species and the support.

As mentioned, the larger nickel phyllosilicate peak for DP16_Cal673 compared to the other Ni(15)/HZSM-5 preparations (Fig. 11) indicates a greater presence of the strong support interacting nickel species. These strong support interacting species of DP16_Cal673 contribute to its higher dispersion, as will be discussed in the next section.

\subsubsection{Particle Size and Dispersion}

TEM, XRD, and $\mathrm{H}_{2}$-chemisorption were utilized to characterize the size and dispersion of the nickel particles (Table 6). TEM mean particle sizes and distributions and the corresponding TEM images for the catalysts are shown in Fig. S3. The TEM and XRD results again are in agreement, and demonstrate that the particle sizes of the different $15 \mathrm{wt} \%$ catalysts are in the 5$12 \mathrm{~nm}$ range. The measured particle sizes are practically the same, except for the DP16_Cal673 catalyst, which has the highest dispersion (7\%) and the smallest particle size (5-7nm) (Table 6). As discussed before, the approximations from chemisorption overestimate the particle size [10].

Of significance are the actual dispersion values and the trends for the dispersion. The first trend is that the $16 \mathrm{~h}$ DP catalysts have higher dispersions, while the $5 \mathrm{~h}$ DP catalysts have lower dispersions. This is consistent with the $16 \mathrm{~h}$ DP catalysts having more nickel-support species present than the $5 \mathrm{~h}$ DP catalysts after calcination; since the nickel-support species are supposed to have stronger interaction with the support. As a result, during the calcination and reduction steps, the particles have more stability and are less susceptible to mobilization during exposure to high temperatures. This allows the particles to have higher dispersion and not aggregate or sinter. The other trend is that as calcination temperature increases, the dispersion decreases. This occurs simply because nickel species tend to mobilize and aggregate more at the higher temperatures than at lower temperatures. By having more stable nickel-support species and using a milder calcination temperature, the DP16_Cal673 catalyst has the greatest dispersion and the smallest particle size. 
As mentioned in section 3.2.1, larger dispersion causes the sample to have less available support surface area. Since greater dispersion indicates that more nickel surface area is present in the form of smaller particles, there will be more particles spread out on the surface of the support (since the mass of nickel is approximately the same for all four catalyst preparations). This increased number of particles on the support surface increases the chance of pore blockage and loss of support surface area, since all nickel particles discussed in these experiments are much larger than the HZSM-5 pores $(5-10 \mathrm{~nm}$ vs. $0.55 \mathrm{~nm})$. Therefore, the main causes of surface area loss are increases in the amount of nickel present (as discussed in section 3.1) or increases in the number of particles on the support as a result of increased dispersion. Despite the surface area loss, the higher dispersion and smaller particle size of the DP16_Cal673 catalyst is desirable, since small particles are important for hydrogenolysis activity and also contribute to the stability in the form of resistance to sintering during recycling as mentioned in section $1[6,7]$.

\subsubsection{Acid Strength}

The acid strength and site density of the four new nickel catalyst preparations are compared to the support without nickel (Table 7). Again, the HZSM-5 exhibits strong acidity ( $\mathrm{E}_{0}$ greater than $100 \mathrm{mV}$ ) [16] due to the presence of Brønsted acid sites. After nickel species are introduced to the support, the acid strength decreases due to the replacement of the Brønsted acid sites with Lewis acid sites and pore blockage which blocks access to acid sites. Similar to section 3.1.2.3, an increase in acid strength from the calcined to the reduced/passivated samples was observed; again, this was attributed to $\mathrm{Ni}^{2+}$ species being reduced and forming small nickel particles which returned some of the strong acid sites that were lost due to pore blockage. For the calcined catalysts, the acid strength was in the moderate strength range for all preparations, but the $16 \mathrm{~h}$ DP catalysts appeared to have a slightly stronger acid strength. This may be attributed to the fact that with longer DP time, more of the lamellar $\mathrm{Ni}^{2+}$ species were formed generating more Lewis acid sites for the support. However, once the nickel species are reduced, this trend no longer exists since the $\mathrm{Ni}^{2+}$ species are reduced into small nickel particles which reduces pore blockage and recovers lost acid sites. Due to the near equal amount of nickel loading between catalysts, there is not a significant difference in acidity. The acid site density again remained similar for all catalyst samples (with an average of $0.0049 \mathrm{mmol} \cdot \mathrm{m}^{-2}$ ).

\subsubsection{Surface Nickel Species}

XPS analysis was also performed on the four Ni/HZSM-5 catalysts after calcination, reduction, passivation, and re-reduction in-situ (1h). As mentioned previously in section 2.2, the reduced catalyst samples are exposed to air during degassing of the sample prior to XPS analysis. The nickel regions of the XPS spectra are depicted in Fig. S4. As with the previous catalyst preparations, XPS analysis of the Ni $2 p$ region revealed two partially overlapped Ni $2 p$ doublets in addition to a satellite peak. The spectra displayed peaks at a $\mathrm{BE}$ of $852.2 \pm 0.2 \mathrm{eV}$ and $870 \mathrm{eV}$, which are assigned to $\mathrm{Ni}^{0}$, while both peaks at $854.4 \pm 0.3 \mathrm{eV}$ and $872 \mathrm{eV}$, correspond to $\mathrm{NiO}$ species [26-30]. The low intensity peaks at about $858 \mathrm{eV}$ and $876 \mathrm{eV}$ are attributed to satellite peaks. The binding energies of the most intense $\mathrm{Ni} 2 \mathrm{p}_{3 / 2}$ component of each catalyst, their relative proportion percentage, and the $\mathrm{Ni} / \mathrm{Si}$ atomic ratio are summarized in Table 8. Similar to the previous study with varying nickel loading, all the catalysts are fully reduced after $4 \mathrm{~h}$ of reduction at $733 \mathrm{~K}$ (confirmed by TPR); it is only after passivation, in-situ reduction, and minor 
air exposure in the pretreatment chamber that the catalyst metal surfaces exhibit slight reoxidation. As shown in Table 8, the catalysts with short DP time exhibited a greater extent of reduction (60-70\%) compared to the long DP time (20-30\%). This difference in the amount of reduced surface nickel can be attributed to the higher dispersion of the long DP time catalysts compared to the short DP time catalysts. Due to the higher dispersion of the long DP time catalysts, there is more nickel surface available to be re-oxidized during the degas step in the pretreatment step prior to XPS analysis. Regarding the Ni/Si atomic ratio, there was not a significant difference in the atomic ratios. This is in agreement with the dispersion data, which show that all these catalysts have similar dispersions.

\section{Conclusion}

Based on the physics and chemical characteristics, optimal processing conditions for the preparation of Ni(15)/HZSM-5 DP16_Cal673 have been proposed. The application of longer DP time, $16 \mathrm{~h}$, and lower calcination temperature, $673 \mathrm{~K}$, led to the highest nickel dispersion reaching, 7\%, and the smallest particle size, around 5-7 nm; both important characteristics for catalytic activity.

Textural properties were not significantly changed with different processing conditions, besides the reduction in surface area from the starting support. The decrease in BET specific surface area was attributed to the blockage of the support's micropores ( $0.55 \mathrm{~nm}$ in diameter) by the metal particles that were formed (5-7 nm and larger in diameter). In addition, the loss of micropores and creation of mesopores for calcined samples were attributed to the formation of plate like structures typical of the lamellar nickel species (1:1 and 2:1 nickel phyllosilicate). When reduced to nickel metal, the mesoporosity was lost since the $\mathrm{Ni}^{2+}$ species were converted to nickel metal.

Presence of $\mathrm{NiO}$ and nickel metal were confirmed by XRD patterns for all catalyst preparations. TPR experiments were able to show that all the catalyst preparations were reducible at the desired reduction conditions $(733 \mathrm{~K}$ for $4 \mathrm{~h}$ ). Results showed that both DP time and nickel nitrate concentration were critical parameters to control the formation and distribution of $\mathrm{Ni}^{2+}$ species. Longer DP times are recommended to produce more of the $1: 1$ nickel phyllosilicate species which have been found to be more stable and resistant to sintering due to the strong support interaction. Lower concentrations of nickel nitrate precursor promoted the formation of the nickel-support species, since the DP time of $5 \mathrm{~h}$ was excessive. The greatest amount of the nickel-support species was observed with catalysts calcined at $673 \mathrm{~K}$, since the $\mathrm{Ni}^{2+}$ species were not transformed nearly to the extent that was achieved with the $873 \mathrm{~K}$ calcination temperature. Using the DP method, nickel particles formed from the stronger nickelsupport species were able to be reduced at the desired reduction temperature after $4 \mathrm{~h}$.

High concentrations of nickel nitrate precursor, $20 \mathrm{wt} \%$, had an adverse impact on the dispersion of $\mathrm{Ni}^{2+}$-support species by promoting the sintering and the formation of larger particles. While the nickel particles for all catalysts besides the $20 \mathrm{wt} \%$ catalyst were similar in size, the one preparation that had the smallest particles and highest dispersion was the DP16_Ca1673 catalyst.

XPS analysis confirmed that the catalysts had similar dispersions. However, with even minor exposure to air re-oxidation of the nickel metal surface occurred (approximately 66\% reduced surface nickel remained for $5 \mathrm{~h} \mathrm{DP}$ catalysts, and only about $28 \%$ for $16 \mathrm{~h}$ DP catalysts). While this is extent of re-oxidation reduces the number of active nickel metal sites especially for 
the $16 \mathrm{~h}$ DP catalysts with higher dispersion, it is not much of a concern. There are still active nickel sites available, and even though the $16 \mathrm{~h}$ DP catalysts have a lower extent of reduced metal surface, they may in fact be much more active than the typical nickel catalyst particles. Also, with these catalysts a flow reaction system may be employed, which could allow for a reduction step prior to reaction and then the reduced catalyst could be used in the reaction system without exposure to air and surface re-oxidation.

As mentioned, DP16_Cal673 had the best properties; small particles (7\% dispersion, 5-7 $\mathrm{nm}$ in diameter), along with the desired strong acidity. The reason that the DP16_Cal673 displayed the best properties is that the long DP time of $16 \mathrm{~h}$ (for a $15 \mathrm{wt} \%$ loading) allowed for the formation of mostly $\mathrm{Ni}^{2+}$-support species, which were then mostly preserved after calcination due to the lower calcination temperature of $673 \mathrm{~K}$. The low calcination temperature also allowed for easier reduction since higher calcination temperatures cause identical nickel species to form stronger interactions between the nickel and the support, which in turn require higher temperatures to reduce. By having the most nickel-support species present prior to reduction, the nickel particles resisted mobilization during reduction and therefore retained a high dispersion and small particle size.

Overall, the DP method was used to create a Ni/HZSM-5 catalyst with high Ni loading (15 $\mathrm{wt} \%$ ), moderate dispersion (7\%), and 5-7 $\mathrm{nm} \mathrm{Ni}$ particles, all of which are located on the exterior surface of the support, while preserving much of the strong acidity and surface area of the HZSM-5 support. The performance of this optimized multifunctional catalyst will be further evaluated in the hydrogenolysis and hydrodeoxygenation of a lignin-derived monomer system. Catalytic activity of these synthesized materials will be compared and related to their textural and chemical properties revealed in this study.

\section{Nomenclature}

Dp particle diameter $(\AA)$

$\lambda \quad \mathrm{CuK} \alpha$ radiation wavelength $(\AA)$

$\beta_{1 / 2} \quad$ full width at half maximum (radians)

$\theta \quad$ Bragg angle (radians)

$\mathrm{D}(\%)$ dispersion $(\%)$

$\mathrm{dp} \quad$ particle diameter $(\mathrm{nm})$

\section{Acknowledgments}

The work was supported by the National Institute of Food and Agriculture, U.S. Department of Agriculture, under Agreement No. 2010-38420-21828, the Project Basal PFB-27 of CONICYT, FONDECYT 1140528, and the Program PMI InEs UCO-1302 of the Chilean Ministry of Education.

\section{References}

[1] F. G. Calvo-Flores, J. A. Dobado, ChemSusChem 2010, 3 (11), 1227-1235.

[2] J. Zakzeski, P. C. A. Bruijnincx, A. L. Jongerius, B. M. Weckhuysen, Chem. Rev. 2010, 110 (6), 3552-3599. 
[3] P. Azadi, O. R. Inderwildi, R. Farnood, D. A. King, Renewable and Sustainable Energy Reviews 2013, 21, 506-523.

[4] A. J. Ragauskas, G. T. Beckham, M. J. Biddy, R. Chandra, F. Chen, M. F. Davis, B. H. Davison, R. A. Dixon, P. Gilna, M. Keller, P. Langan, A. K. Naskar, J. N. Saddler, T. J. Tschaplinski, G. A. Tuskan, C. E. Wyman, Science 2014, 344 (6185).

[5] P. Burattin, M. Che, C. Louis, The Journal of Physical Chemistry B 1998, 102 (15), 2722-2732.

[6] P. Burattin, M. Che, C. Louis, The Journal of Physical Chemistry B 2000, 104 (45), 10482-10489.

[7] W. Song, C. Zhao, J. A. Lercher, Chemistry - A European Journal 2013, 19 (30), 98339842 .

[8] J. He, C. Zhao, J. A. Lercher, J. Am. Chem. Soc. 2012, 134 (51), 20768-20775.

[9] J. He, C. Zhao, D. Mei, J. A. Lercher, Journal of Catalysis 2014, 309 (0), 280-290.

[10] W. Song, Y. Liu, E. Barath, C. Zhao, J. A. Lercher, Green Chem. 2015, 17 (2), 12041218.

[11] R. Nares, J. Ramírez, A. Gutiérrez-Alejandre, C. Louis, T. Klimova, The Journal of Physical Chemistry B 2002, 106 (51), 13287-13293.

[12] M. V. Sivaiah, S. Petit, M. F. Beaufort, D. Eyidi, J. Barrault, C. Batiot-Dupeyrat, S. Valange, Microporous and Mesoporous Materials 2011, 140 (1-3), 69-80.

[13] X. Kong, Y. Zhu, H. Zheng, X. Li, Y. Zhu, Y.-W. Li, ACS Catalysis 2015, 5 (10), 59145920.

[14] B.-H. Chen, Z.-S. Chao, H. He, C. Huang, Y.-J. Liu, W.-J. Yi, X.-L. Wei, J.-F. An, Dalton Transactions 2016, 45 (6), 2720-2739.

[15] J. S. Smith, P. A. Thrower, M. A. Vannice, J. Catal 1981, 68 (2), 270-285.

[16] R. Cid, G. Pecchi, Applied Catalysis 1985, 14 (0), 15-21.

[17] K. S. W. Sing, Pure \& Appl. Chem. 1982, 54 (11), 2201-2218.

[18] K. V. Rao, C. S. Sunandana, Journal of Physics and Chemistry of Solids 2008, 69 (1), $87-$ 96.

[19] Z. Janusz, Ł Iwona, B.-P. Ewa, M. Beata, Nanotechnology 2010, 21 (14), 145308. 
[20] M. El-Kemary, N. Nagy, I. El-Mehasseb, Materials Science in Semiconductor Processing 2013, 16 (6), 1747-1752.

[21] E. A. Owen, E. L. Yates, Philos. Mag. 1936, 21, 809-819.

[22] F. Davar, Z. Fereshteh, M. Salavati-Niasari, Journal of Alloys and Compounds 2009, 476 (1-2), 797-801.

[23] V. Mohan, C. Raghavendra, C. V. Pramod, B. D. Raju, K. S. Rama Rao, RSC Advances 2014, 4 (19), 9660-9668.

[24] W. C. Conner, J. L. Falconer, Chem. Rev. 1995, 95 (3), 759-788.

[25] B. Pawelec, R. Mariscal, R. M. Navarro, J. M. Campos-Martin, J. L. G. Fierro, Applied Catalysis A: General 2004, 262 (2), 155-166.

[26] V. M. Shinde, G. Madras, Applied Catalysis B: Environmental 2013, 132-133, 28-38.

[27] S.-C. Qi, X.-Y. Wei, Z.-M. Zong, J.-I. Hayashi, X.-H. Yuan, L.-B. Sun, ChemCatChem 2013, 5 (12), 3543-3547.

[28] A. B. Dongil, L. Pastor-Pérez, A. Sepúlveda-Escribano, R. García, N. Escalona, Fuel 2016, 172, 65-69.

[29] A. B. Dongil, I. T. Ghampson, R. Garcia, J. L. G. Fierro, N. Escalona, RSC Advances 2016, 6 (4), 2611-2623.

[30] A. B. Dongil, B. Bachiller-Baeza, I. Rodriguez-Ramos, J. L. G. Fierro, N. Escalona, RSC Advances 2016, 6 (32), 26658-26667.

[31] G. Lagos, R. García, A. L. Agudo, M. Yates, J. L. G. Fierro, F. J. Gil-Llambías, N. Escalona, Applied Catalysis A: General 2009, 358 (1), 26-31.

[32] K. Leiva, C. Sepúlveda, R. García, J. L. G. Fierro, P. Reyes, I. T. Ghampson, P. Baeza, M. Villarroel, N. Escalona, Journal of the Chilean Chemical Society 2013, 58, 19471951.

[33] N. Martínez, R. García, J. L. G. Fierro, C. Wheeler, R. N. Austin, J. R. Gallagher, J. T. Miller, T. R. Krause, N. Escalona, C. Sepúlveda, Fuel 2016, 186, 112-121.

[34] C. Sepúlveda, R. García, P. Reyes, I. T. Ghampson, J. L. G. Fierro, D. Laurenti, M. Vrinat, N. Escalona, Applied Catalysis A: General 2014, 475, 427-437.

[35] M. D. Romero, J. A. Calles, A. Rodríguez, J. C. Cabanelas, Ind. Eng. Chem. Res. 1998, 37 (10), 3846-3852. 
[36] Q. Zhang, K. Qiu, B. Li, T. Jiang, X. Zhang, L. Ma, T. Wang, Fuel 2011, 90 (11), 34683472. 
Fig. 1. $\mathrm{N}_{2}$ adsorption-desorption isotherms with increasing Ni loading for a) calcined Ni(x)/HZSM-5 catalysts and b) calcined, reduced, and passivated Ni(x)/HZSM-5 catalysts (DP time of $5 \mathrm{~h}$ ).

\section{(Print with color)}

Fig. 2. $\mathrm{N}_{2}$ BJH desorption mesopore size distribution for a) calcined $\mathrm{Ni}(\mathrm{x}) / \mathrm{HZSM}-5$ catalysts and b) calcined, reduced, and passivated $\mathrm{Ni}(\mathrm{x}) / \mathrm{HZSM}-5$ catalysts (DP time of $5 \mathrm{~h}$ ).

\section{(Print with color)}

Fig 3. $\mathrm{CO}_{2}$ DFT micropore size distribution for a) calcined $\mathrm{Ni}(\mathrm{x}) / \mathrm{HZSM}-5$ catalysts and b) calcined, reduced, and passivated $\mathrm{Ni}(\mathrm{x}) / \mathrm{HZSM}-5$ catalysts (DP time of $5 \mathrm{~h}$ ).

\section{(Print with color)}

Fig. 4. X-ray diffraction (XRD) for a) calcined $\mathrm{Ni}(\mathrm{x}) / \mathrm{HZSM}-5$ catalysts and $\mathrm{b}$ ) calcined, reduced, and passivated $\mathrm{Ni}(\mathrm{x}) / \mathrm{HZSM}-5$ catalysts (DP time of $5 \mathrm{~h}$ ).

\section{(Print with color)}

Fig. 5. Temperature programmed reduction (TPR) for Ni(x)/HZSM-5 catalysts (DP time of 5 h).

\section{(Print with color)}

Fig. 6. Ni/Si atomic ratio, from XPS, correlation to nickel loading.

Fig. 7. $\mathrm{N}_{2}$ adsorption-desorption isotherms with increasing DP time and calcination temperature for a) calcined $\mathrm{Ni}(15) / \mathrm{HZSM}-5$ catalysts and b) calcined, reduced, and passivated Ni(15)/HZSM-5 catalysts.

\section{(Print with color)}

Fig. 8. $N_{2} B J H$ desorption mesopore size distribution for a) calcined $\mathrm{Ni}(15) / \mathrm{HZSM}-5$ catalysts and $b$ ) calcined, reduced, and passivated $\mathrm{Ni}(15) / \mathrm{HZSM}-5$ catalysts.

\section{(Print with color)}

Fig. 9. $\mathrm{CO}_{2}$ DFT micropore size distribution for a) calcined $\mathrm{Ni}(15) / \mathrm{HZSM}-5$ catalysts and b) calcined, reduced, and passivated $\mathrm{Ni}(15) / \mathrm{HZSM}-5$ catalysts.

\section{(Print with color)}

Fig. 10. X-ray diffraction (XRD) for a) calcined Ni(15)/HZSM-5 catalysts and b) calcined, reduced, and passivated $\mathrm{Ni}(15) / \mathrm{HZSM}-5$ catalysts.

\section{(Print with color)}

Fig. 11. Temperature programmed reduction (TPR) for Ni(15)/HZSM-5 catalysts.

*This data set had to be adjusted due to an error in the temperature recording. When all tests were repeated, the locations of the peaks for the other three samples were the same, but DP16_Cal673 was shifted to where it is currently located in the figure.

(Print with color) 
Table 1

Nickel loading and textural properties of the catalysts (DP time of 5 h) which were calcined at $873 \mathrm{~K}$ and nickel catalysts were reduced at $733 \mathrm{~K}$.

\begin{tabular}{|c|c|c|c|c|c|}
\hline Catalyst & $\begin{array}{c}\text { Ni Content }{ }^{\mathrm{a}} \\
(\%)\end{array}$ & $\underset{\left(\mathbf{m}^{2} \cdot \mathbf{g}^{-1}\right)}{\mathbf{S}_{\mathrm{BET}}}$ & $\begin{array}{c}V_{p^{b}}^{b} \\
\left(\mathrm{~cm}^{3} \cdot g^{-1}\right)\end{array}$ & $\begin{array}{c}V_{\text {micro }} \\
\left(\mathrm{cm}^{3} \cdot \mathrm{g}^{-1}\right)\end{array}$ & $\begin{array}{c}V_{\text {meso }}^{d} \\
\left(\mathrm{~cm}^{3} \cdot \mathrm{g}^{-1}\right)\end{array}$ \\
\hline HZSM-5 $\left(\mathrm{SiO}_{2} / \mathrm{Al}_{2} \mathrm{O}_{3}=20\right)$ & -- & 420 & 0.22 & 0.18 & 0.04 \\
\hline \multicolumn{6}{|l|}{ (calcined) } \\
\hline $\mathrm{Ni}(5) / \mathrm{HZSM}-5$ & 5.0 & 312 & 0.16 & 0.15 & 0.01 \\
\hline Ni(10)/HZSM-5 & 10.6 & 309 & 0.19 & 0.15 & 0.04 \\
\hline Ni(12.5)/HZSM-5 & 12.2 & 307 & 0.20 & 0.15 & 0.05 \\
\hline Ni(15)/HZSM-5 & 13.3 & 303 & 0.20 & 0.14 & 0.06 \\
\hline $\mathrm{Ni}(20) / \mathrm{HZSM}-5$ & 16.2 & 255 & 0.18 & 0.12 & 0.06 \\
\hline \multicolumn{6}{|l|}{ (reduced and passivated) } \\
\hline $\mathrm{Ni}(5) / \mathrm{HZSM}-5$ & 5.0 & 247 & 0.13 & 0.12 & 0.01 \\
\hline Ni(10)/HZSM-5 & 10.6 & 254 & 0.14 & 0.12 & 0.02 \\
\hline $\mathrm{Ni}(12.5) / \mathrm{HZSM}-5$ & 12.2 & 325 & 0.20 & 0.15 & 0.05 \\
\hline Ni(15)/HZSM-5 & 13.3 & 298 & 0.18 & 0.15 & 0.03 \\
\hline $\mathrm{Ni}(20) / \mathrm{HZSM}-5$ & 16.2 & 242 & 0.13 & 0.11 & 0.02 \\
\hline \multicolumn{6}{|c|}{ a $\quad$ Content determined by ICP-OES } \\
\hline \multicolumn{6}{|c|}{$\mathrm{V}_{\mathrm{p}}=$ total pore volume } \\
\hline \multicolumn{6}{|c|}{$\mathrm{V}_{\text {micro }}=$ micropore volume } \\
\hline \multicolumn{6}{|c|}{$\mathrm{V}_{\text {meso }}=$ mesopore volume } \\
\hline
\end{tabular}




\section{Table 2}

Average particle size from TEM and $\mathrm{H}_{2}$-chemisorption, and nickel dispersions obtained from $\mathrm{H}_{2}$-chemisorption. Catalysts (DP time of $5 \mathrm{~h}$ ) were calcined, reduced, and passivated for the TEM and XRD.

\begin{tabular}{lcccc}
\hline \multirow{2}{*}{ Catalyst } & \multicolumn{3}{c}{ Nickel particle size (nm) } & \multirow{2}{*}{$\begin{array}{c}\text { Ni Dispersion } \\
(\boldsymbol{\%})\end{array}$} \\
\cline { 2 - 4 } & TEM & XRD & $\mathbf{H}_{\mathbf{2}}$-Chemisorption & 3.4 \\
$\mathrm{Ni}(5) / H Z S M-5$ & $14 \pm 6$ & 22 & 29 & 3.7 \\
$\mathrm{Ni}(10) / H Z S M-5$ & $8 \pm 3$ & 10 & 28 & 3.3 \\
$\mathrm{Ni}(12.5) / H Z S M-5$ & $9 \pm 2$ & 10 & 31 & 3.3 \\
$\mathrm{Ni}(15) / \mathrm{HZSM}-5$ & $8 \pm 3$ & 8 & 31 & 2.3 \\
$\mathrm{Ni}(20) / \mathrm{HZSM}-5$ & $10 \pm 4$ & 13 & 45 & \\
\hline
\end{tabular}


Table 3

Acid strength and density obtained from potentiometric titration method.

\begin{tabular}{lcccc}
\hline \multirow{2}{*}{ Catalyst } & \multicolumn{2}{c}{ Acid Strength, $\mathbf{E}_{\mathbf{0}} \mathbf{( m V )}$} & \multicolumn{2}{c}{ Acid Density $\left(\mathbf{m m o l} \cdot \mathbf{m}^{-2}\right)$} \\
\cline { 2 - 5 } & Calcined & Reduced/Passivated & Calcined & Reduced/Passivated \\
\hline HZSM-5 & 374 & -- & 0.0034 & -- \\
$\mathrm{Ni}(5) / H Z S M-5$ & -64 & 36 & 0.0046 & 0.0057 \\
$\mathrm{Ni}(10) / \mathrm{HZSM-5}$ & 11 & 129 & 0.0047 & 0.0055 \\
$\mathrm{Ni}(12.5) / \mathrm{HZSM}-5$ & 36 & 173 & 0.0048 & 0.0044 \\
$\mathrm{Ni}(15) / \mathrm{HZSM}-5$ & 37 & 289 & 0.0050 & 0.0048 \\
$\mathrm{Ni}(20) / \mathrm{HZSM}-5$ & 40 & 291 & 0.0064 & 0.0059 \\
\hline
\end{tabular}

$\mathrm{E}_{0}>100 \mathrm{mV}=$ very strong acid, $\mathrm{E}_{0}<-100 \mathrm{mV}=$ very weak acid 
Table 4

XPS binding energies (eV) and surface atomic ratios for calcined, reduced, passivated, and in-situ re-reduced $\mathrm{Ni}(\mathrm{x}) / \mathrm{HZSM}-5$ catalysts. Catalysts had minor exposure to air between the reduction pretreatment and XPS analysis.

\begin{tabular}{|c|c|c|c|c|c|c|}
\hline \multirow{2}{*}{ Catalyst } & \multirow{2}{*}{$\begin{array}{c}\text { Si 2p } \\
(\mathbf{e V})\end{array}$} & \multicolumn{4}{|c|}{$\mathrm{Ni} 2 \mathbf{p}_{3 / 2}$} & \multirow{2}{*}{$\begin{array}{c}\text { Atomic } \\
\text { Ratio } \\
\text { (Ni/Si) }\end{array}$} \\
\hline & & $\mathrm{Ni}(\mathrm{eV})$ & $\%$ Reduced & $\mathrm{NiO}(\mathrm{eV})$ & $\%$ Unreduced & \\
\hline Ni(5)/HZSM-5 & 103.3 & 852.4 & 65 & 854.7 & 35 & 0.306 \\
\hline Ni(10)/HZSM-5 & 103.2 & 852.2 & 74 & 854.6 & 26 & 1.115 \\
\hline Ni(12.5)/HZSM-5 & 103.2 & 852.0 & 58 & 854.2 & 42 & 1.178 \\
\hline Ni(15)/HZSM-5 & 103.3 & 852.2 & 61 & 854.4 & 39 & 1.425 \\
\hline $\mathrm{Ni}(20) / \mathrm{HZSM}-5$ & 103.3 & 852.2 & 70 & 855.3 & 30 & 2.169 \\
\hline
\end{tabular}


Table 5

Nickel loading and textural properties of the catalysts.

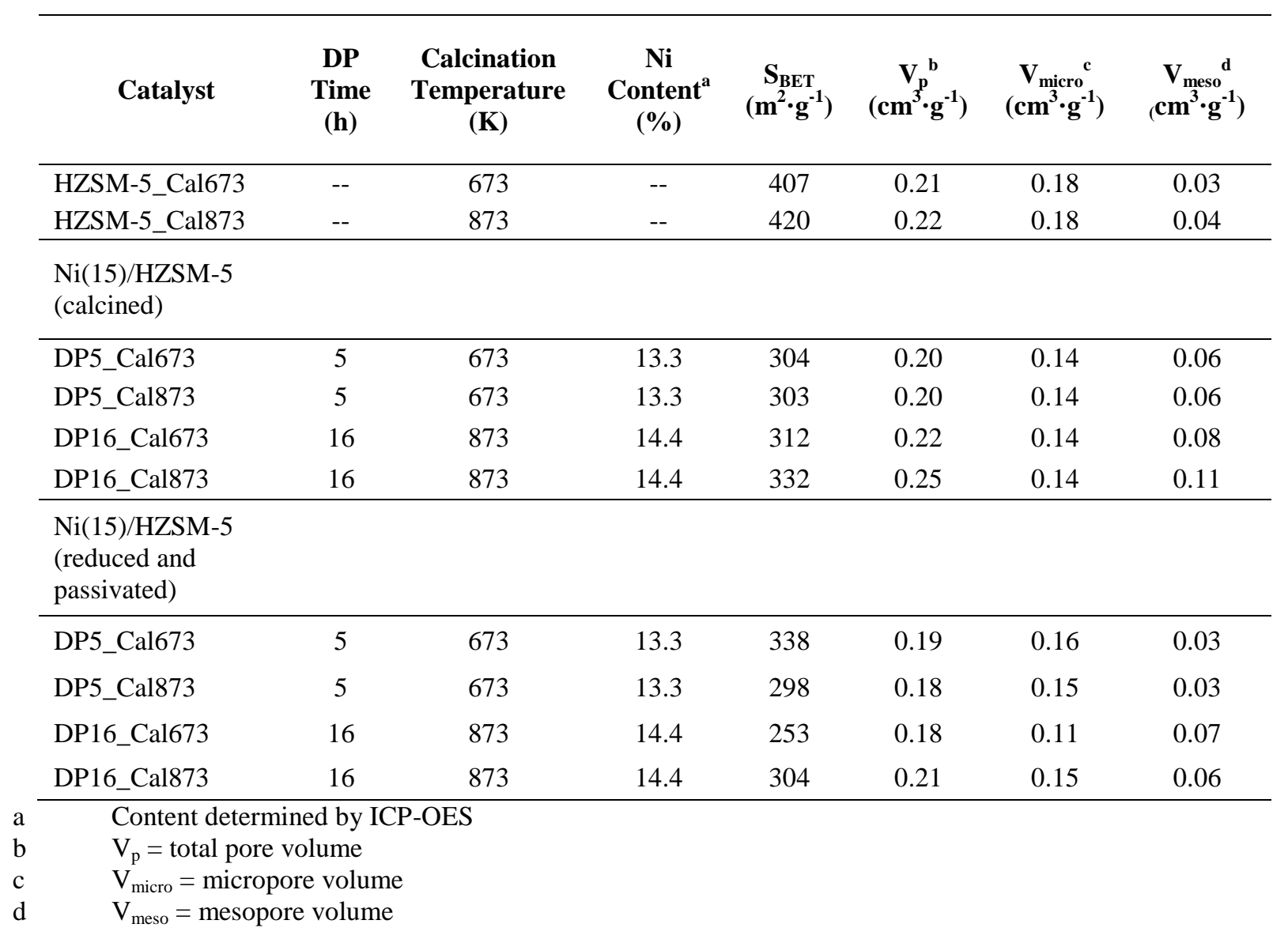




\section{Table 6}

Average particle size from TEM and $\mathrm{H}_{2}$-chemisorption, and nickel dispersions obtained from $\mathrm{H}_{2}$ - chemisorption. Catalysts were calcined, reduced, and passivated for the TEM and XRD.

\begin{tabular}{lcccc}
\hline \multirow{2}{*}{ Ni(15)/HZSM-5 } & \multicolumn{3}{c}{ Nickel particle size (nm) } & Ni Dispersion \\
\cline { 2 - 4 } & TEM & XRD & $\begin{array}{c}\mathbf{H}_{2^{-}} \\
\text {Chemisorption }\end{array}$ & (\%) \\
\hline DP5_Ca1673 & $9 \pm 3$ & 8 & 24 & 4.2 \\
DP16_Ca1673 & $5 \pm 2$ & 7 & 14 & 7.0 \\
DP5_Ca1873 & $8 \pm 3$ & 8 & 31 & 3.3 \\
DP16_Cal873 & $9 \pm 3$ & 8 & 20 & 5.1 \\
\hline
\end{tabular}


Table 7

Acid strength and density obtained from potentiometric titration method.

\begin{tabular}{lcccc}
\hline \multirow{2}{*}{ Catalyst } & \multicolumn{2}{c}{ Acid Strength, $\mathbf{E}_{\mathbf{0}}(\mathbf{m V})$} & \multicolumn{2}{c}{ Acid Density $\left(\mathbf{m m o l} \cdot \mathbf{m}^{-\mathbf{2}}\right)$} \\
\cline { 2 - 5 } & Calcined & Reduced/Passivated & Calcined & Reduced/Passivated \\
\hline HZSM-5_Ca1673 & 323 & -- & 0.0036 & -- \\
DP5_Cal673 & -16 & 220 & 0.0049 & 0.0044 \\
DP16_Cal673 & 69 & 261 & 0.0058 & 0.0071 \\
HZSM-5_Cal873 & 374 & -- & 0.0034 & -- \\
DP5_Ca1873 & 37 & 289 & 0.0050 & 0.0048 \\
DP16_Ca1873 & 100 & 236 & 0.0048 & 0.0053 \\
\hline
\end{tabular}

$\mathrm{E}_{0}>100 \mathrm{mV}=$ very strong acid, $\mathrm{E}_{0}<-100 \mathrm{mV}=$ very weak acid 
Table 8

XPS binding energies (eV) and surface atomic ratios for calcined, reduced, passivated, and in-situ re-reduced Ni(15)/HZSM-5 catalysts. Catalysts had minor exposure to air between the reduction pretreatment and XPS analysis.

\begin{tabular}{lcccccc}
\hline \multirow{2}{*}{ Ni(15)/HZSM-5 } & \multirow{2}{*}{$\begin{array}{c}\text { Si 2p } \\
(\mathbf{e V})\end{array}$} & $\mathbf{N i}(\mathbf{e V})$ & $\begin{array}{c}\text { Reduced } \\
\mathbf{( \% )}\end{array}$ & $\mathbf{N i O}(\mathbf{e V})$ & $\begin{array}{c}\text { Unreduced } \\
\mathbf{( \% )}\end{array}$ & $\begin{array}{c}\text { Atomic } \\
\text { Ratio } \\
(\mathbf{N i} / \mathbf{S i})\end{array}$ \\
\hline DP5_Cal673 & 103.1 & 852.1 & 72 & 854.4 & 28 & 1.384 \\
DP5_Cal873 & 103.3 & 852.2 & 61 & 854.4 & 39 & 1.425 \\
DP16_Cal673 & 103.3 & 852.3 & 24 & 854.7 & 76 & 1.444 \\
DP16_Cal873 & 103.3 & 852.2 & 32 & 855.0 & 68 & 1.480 \\
\hline
\end{tabular}



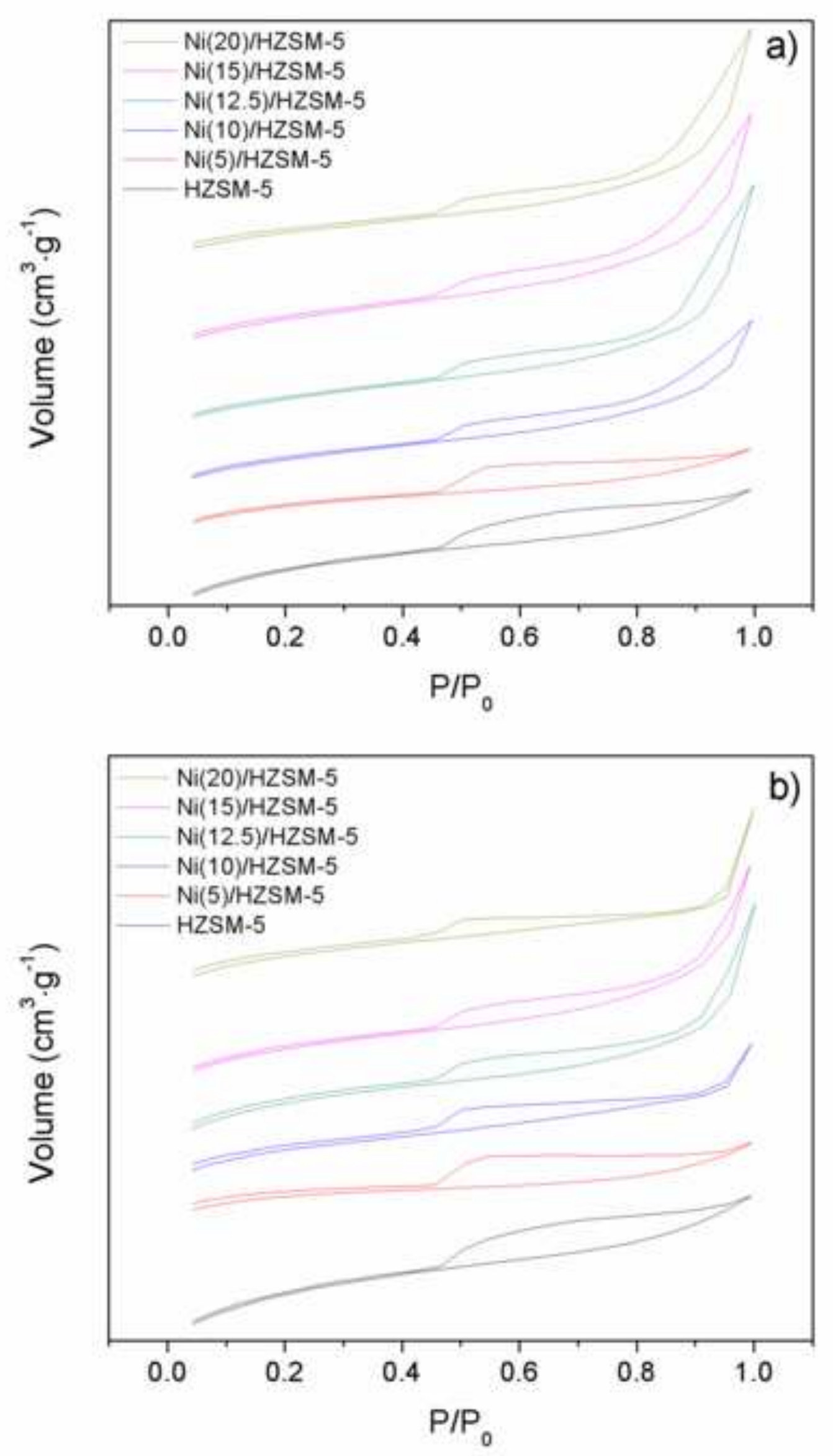

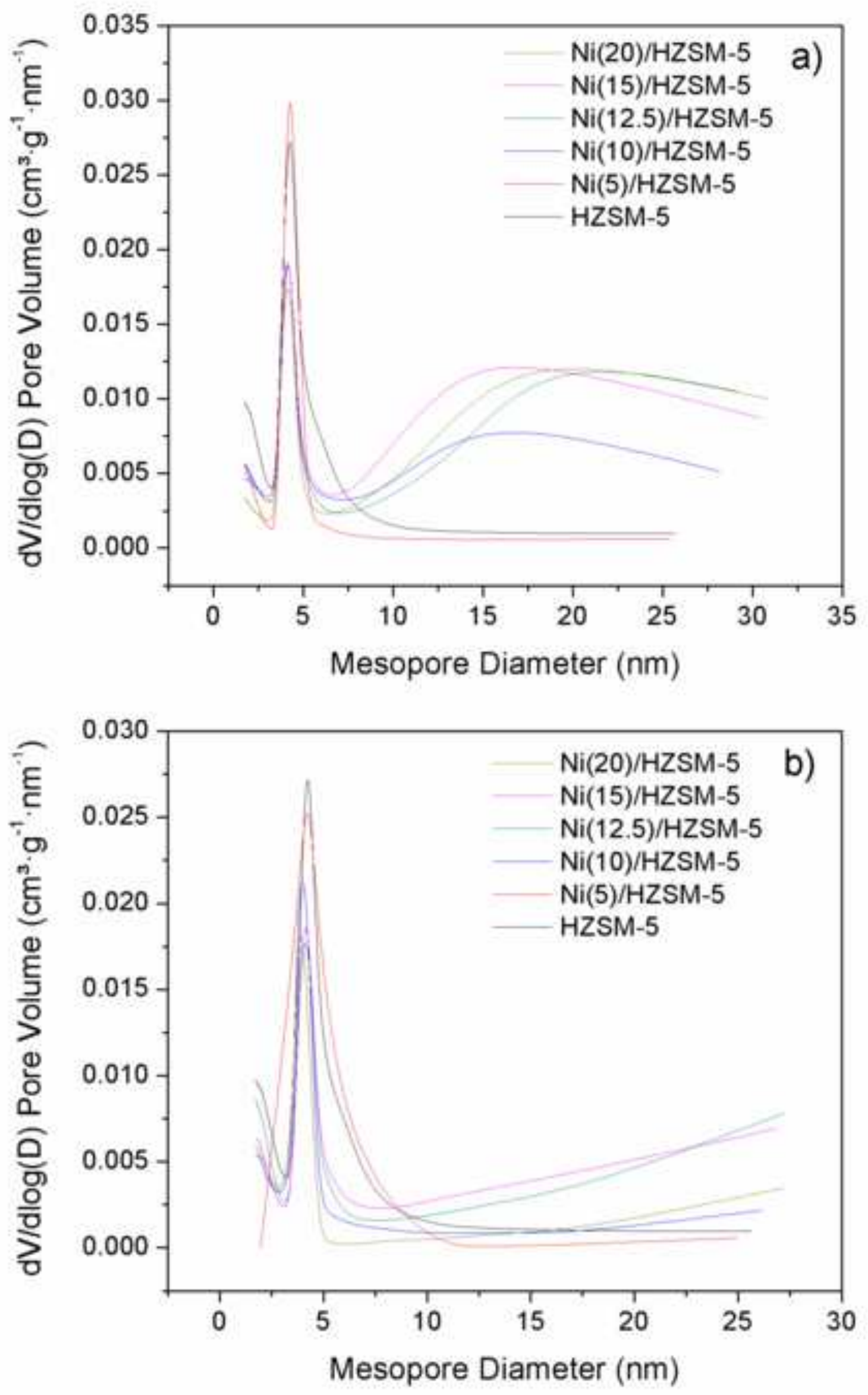

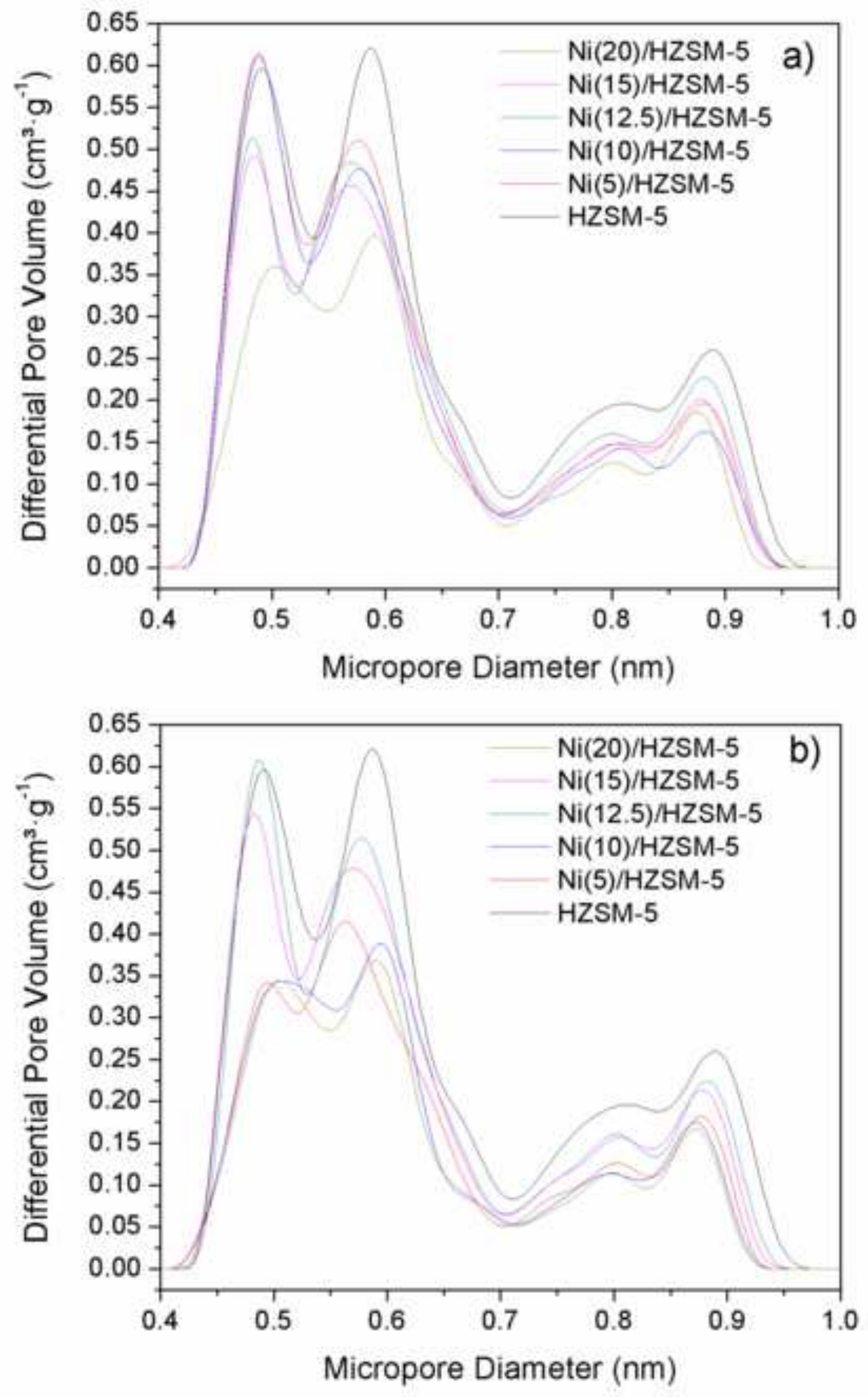
NiO: $37.25^{\circ}, 43.28^{\circ}, 62.87^{\circ}$

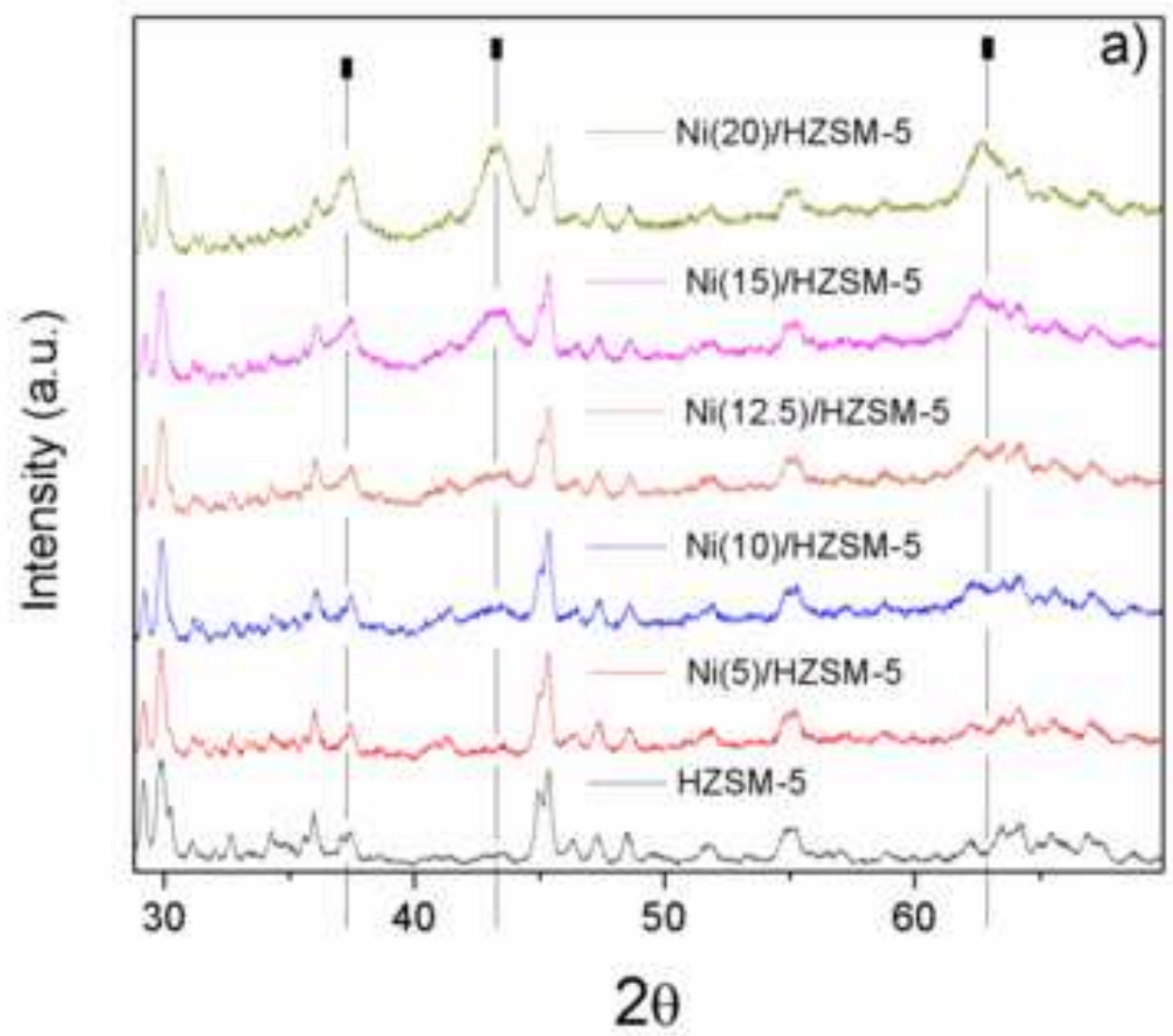

Ni: $44.49^{\circ}, 51.84^{\circ}$

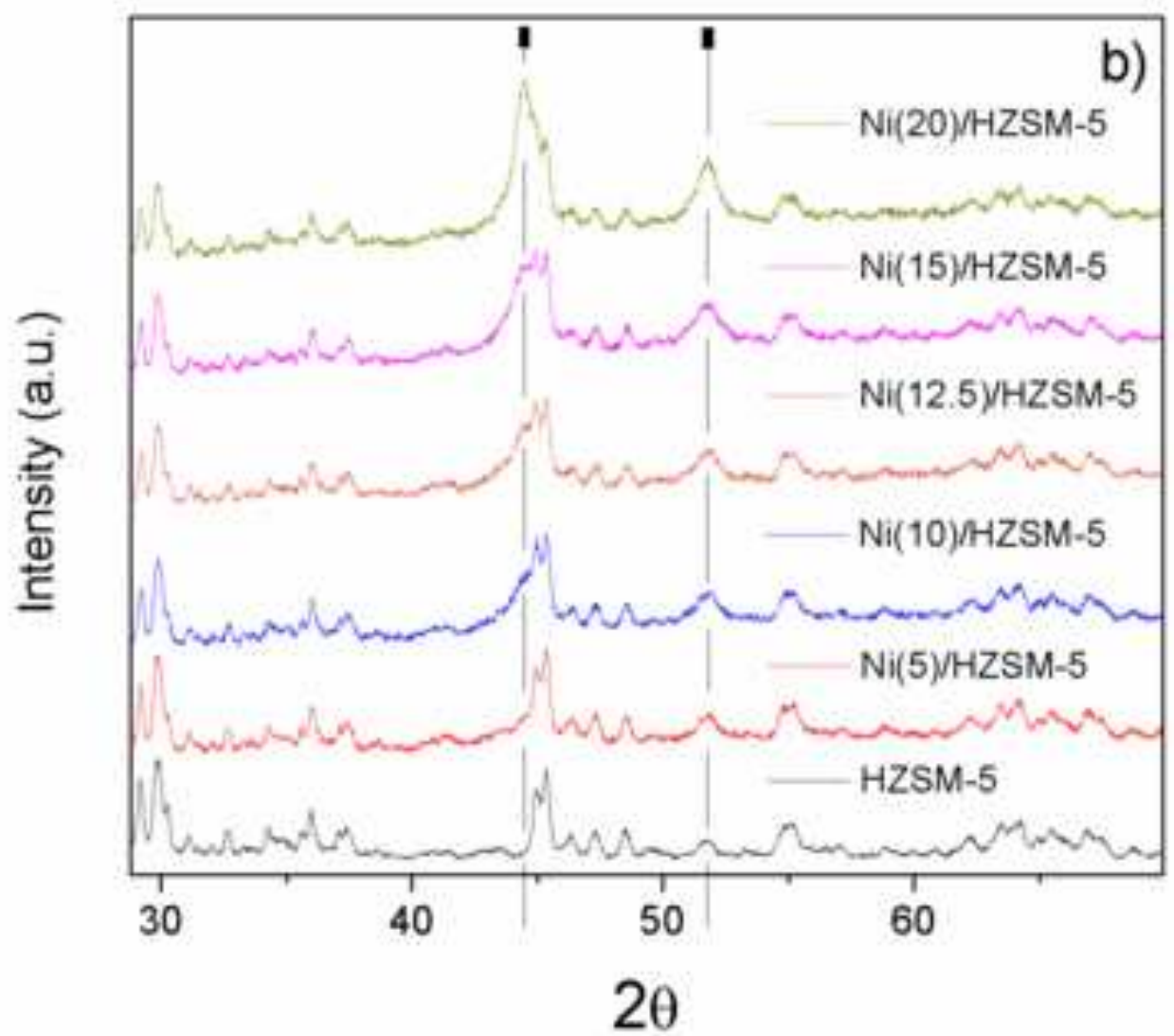




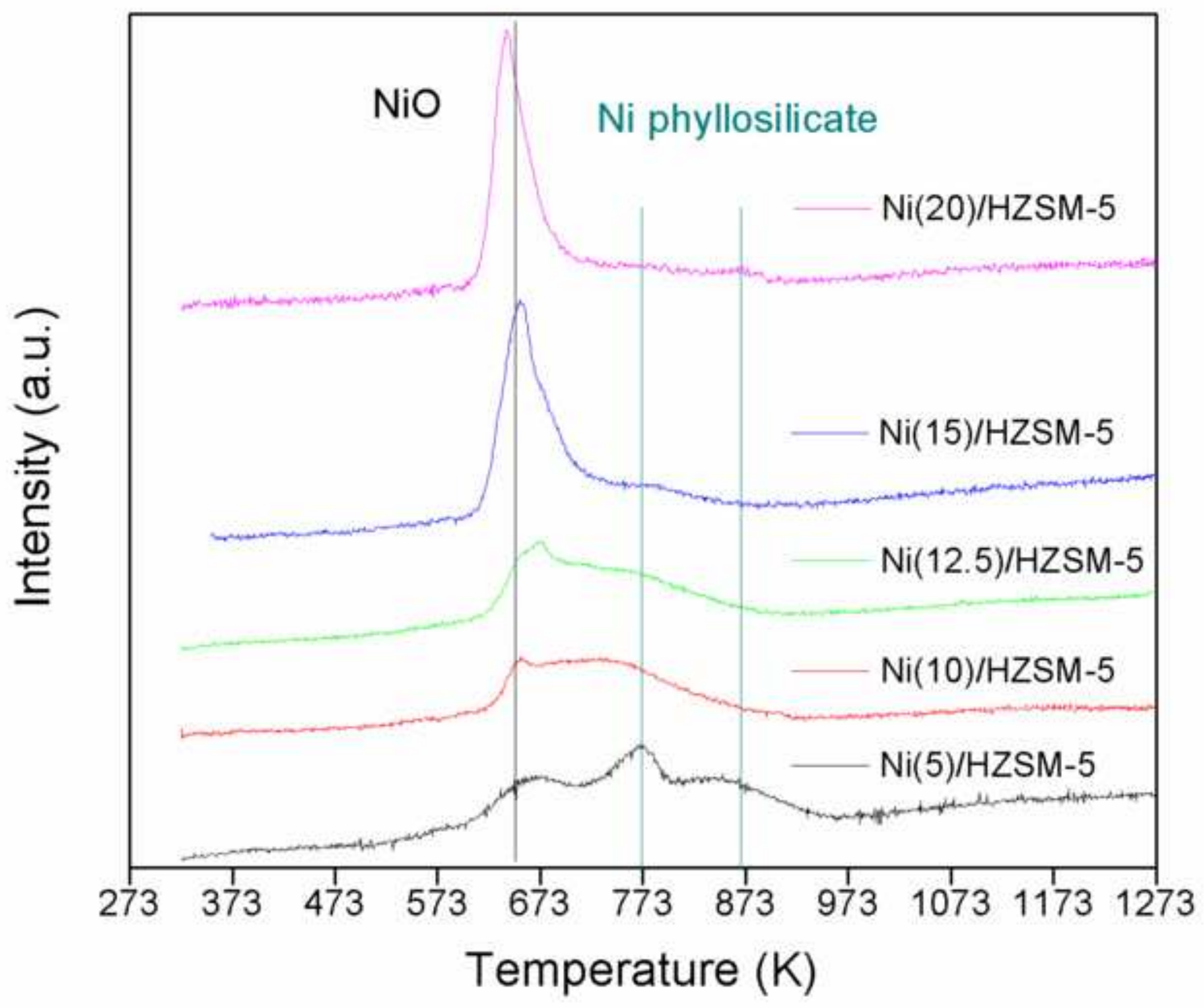




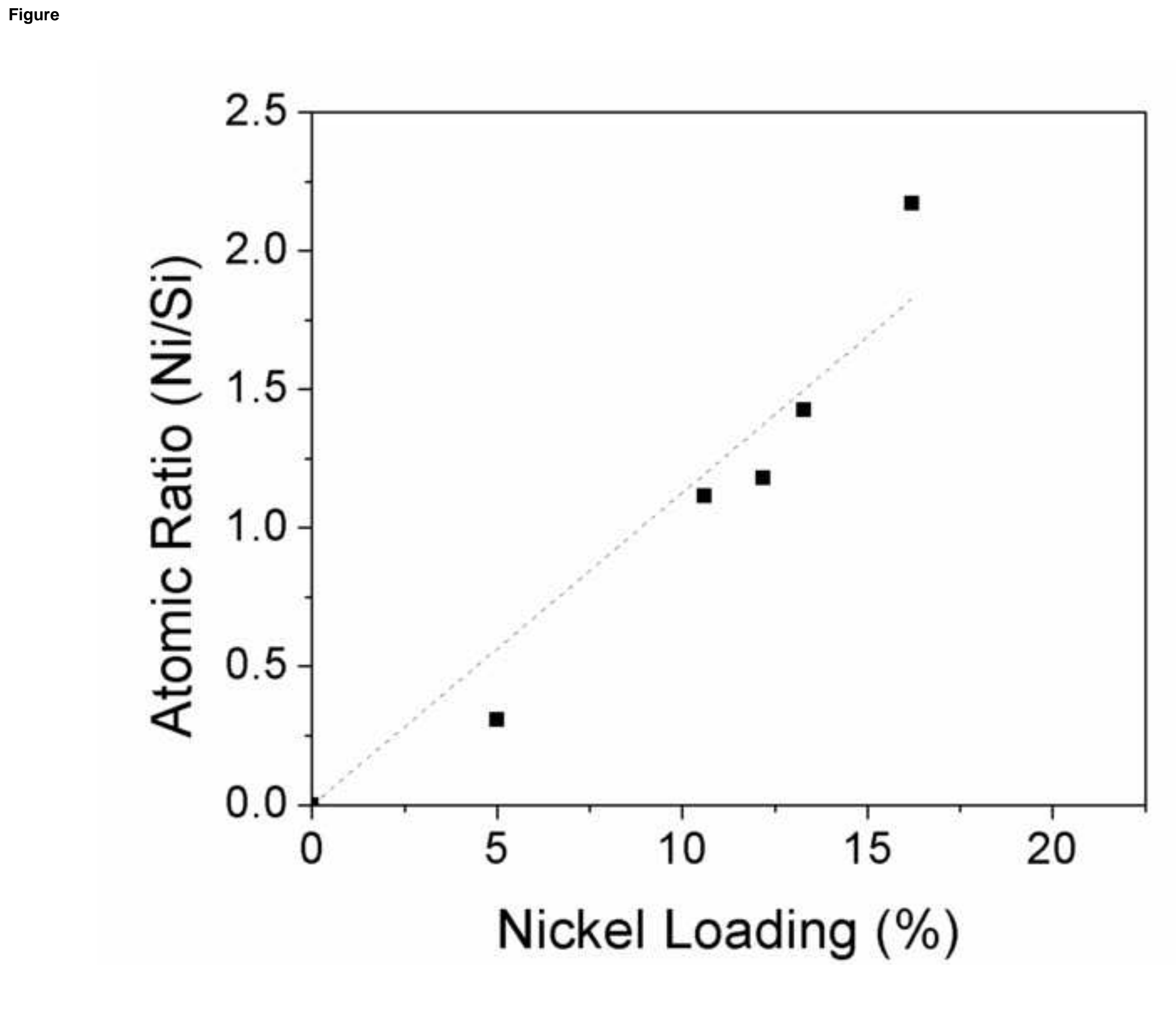

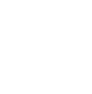

.
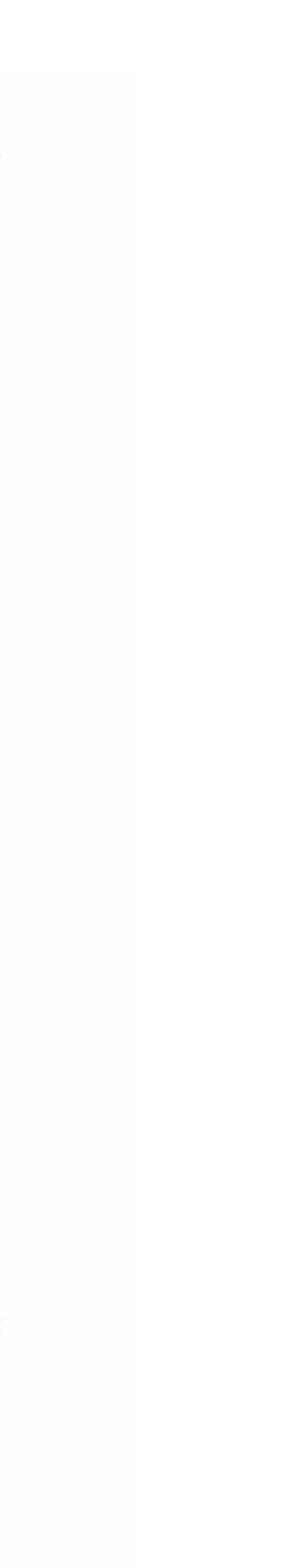

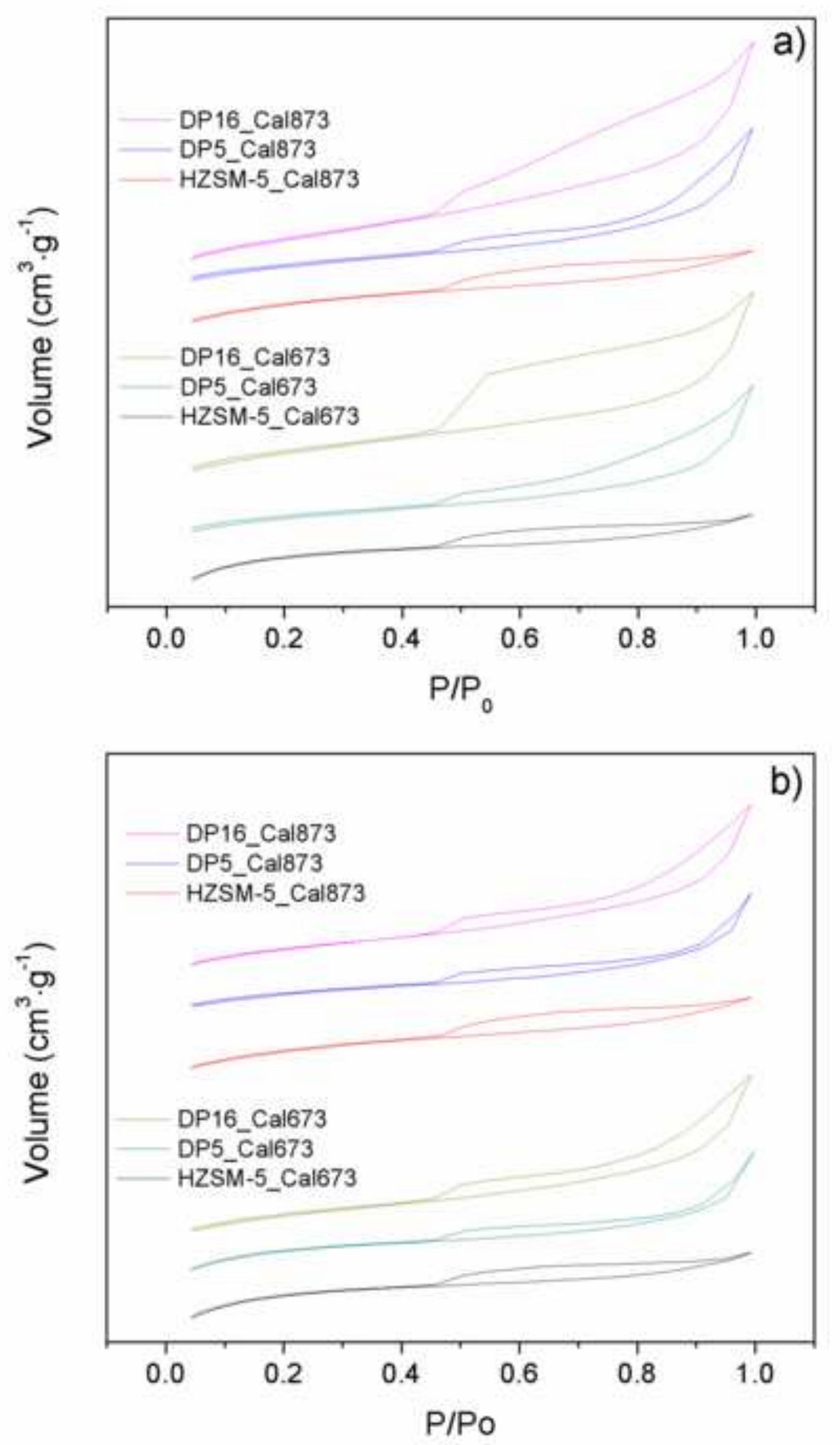

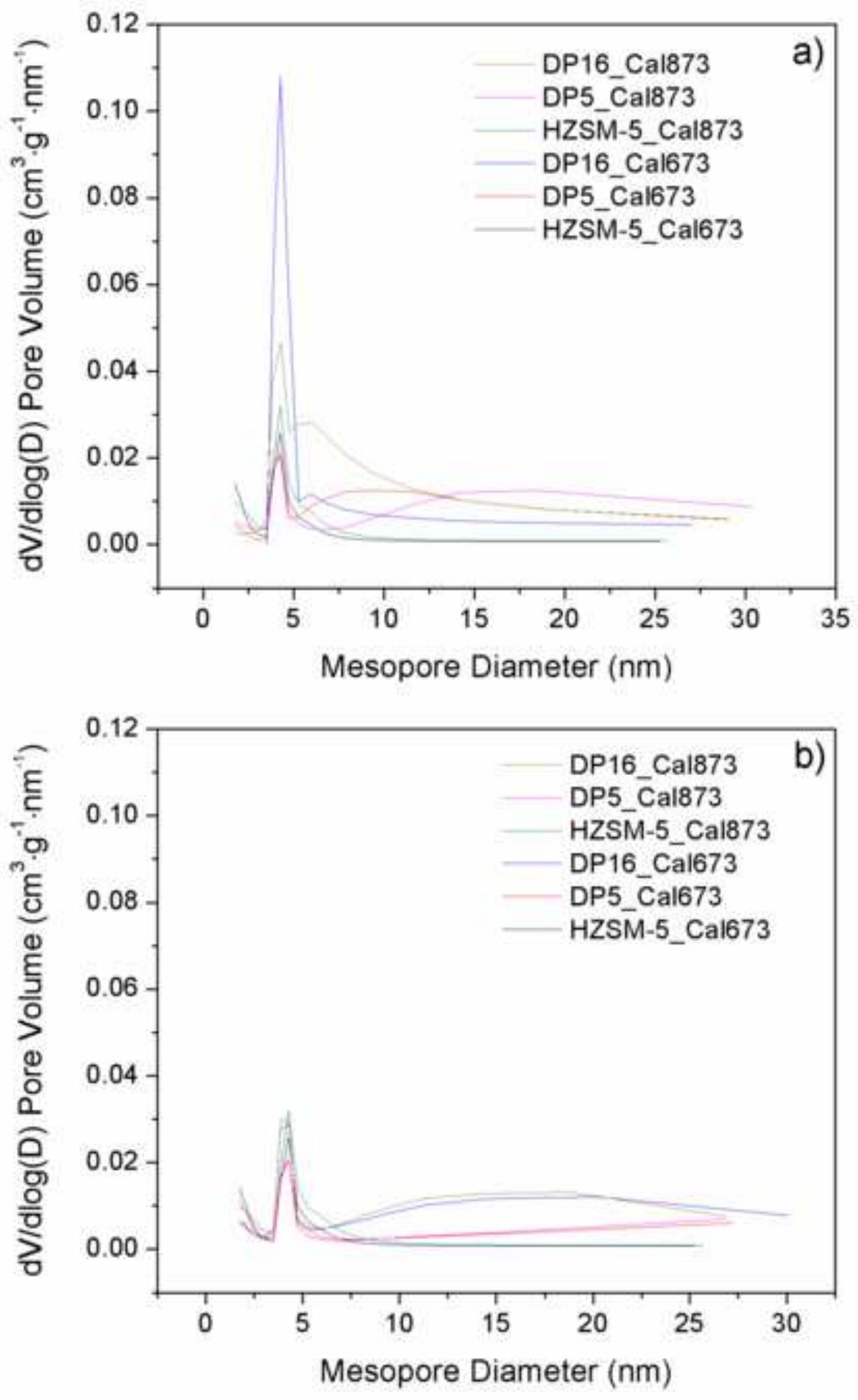

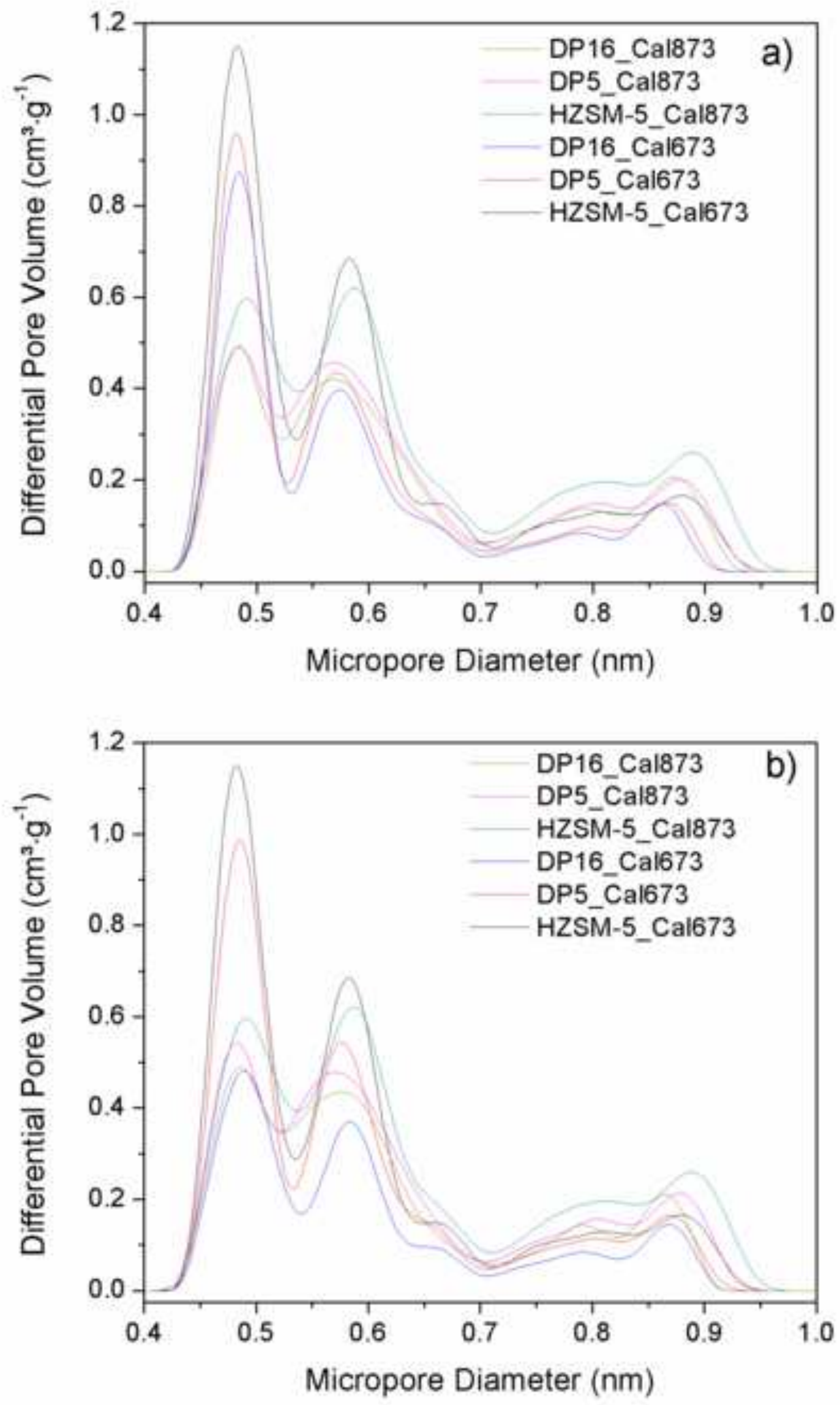
$\mathrm{NiO}: 37.25^{\circ}, 43.28^{\circ}, 62.87^{\circ}$

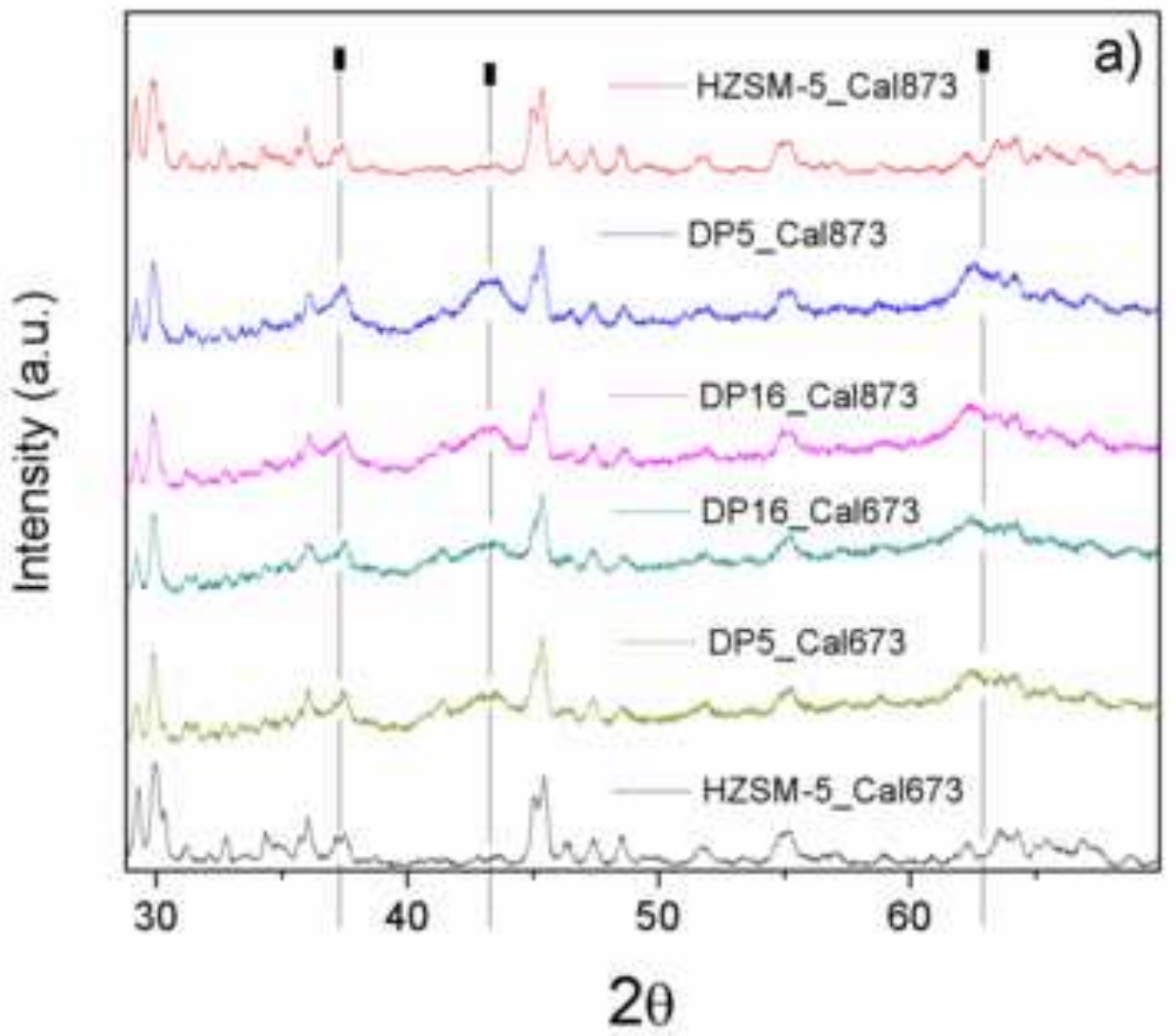

Ni: $44.49^{\circ}, 51.84^{\circ}$

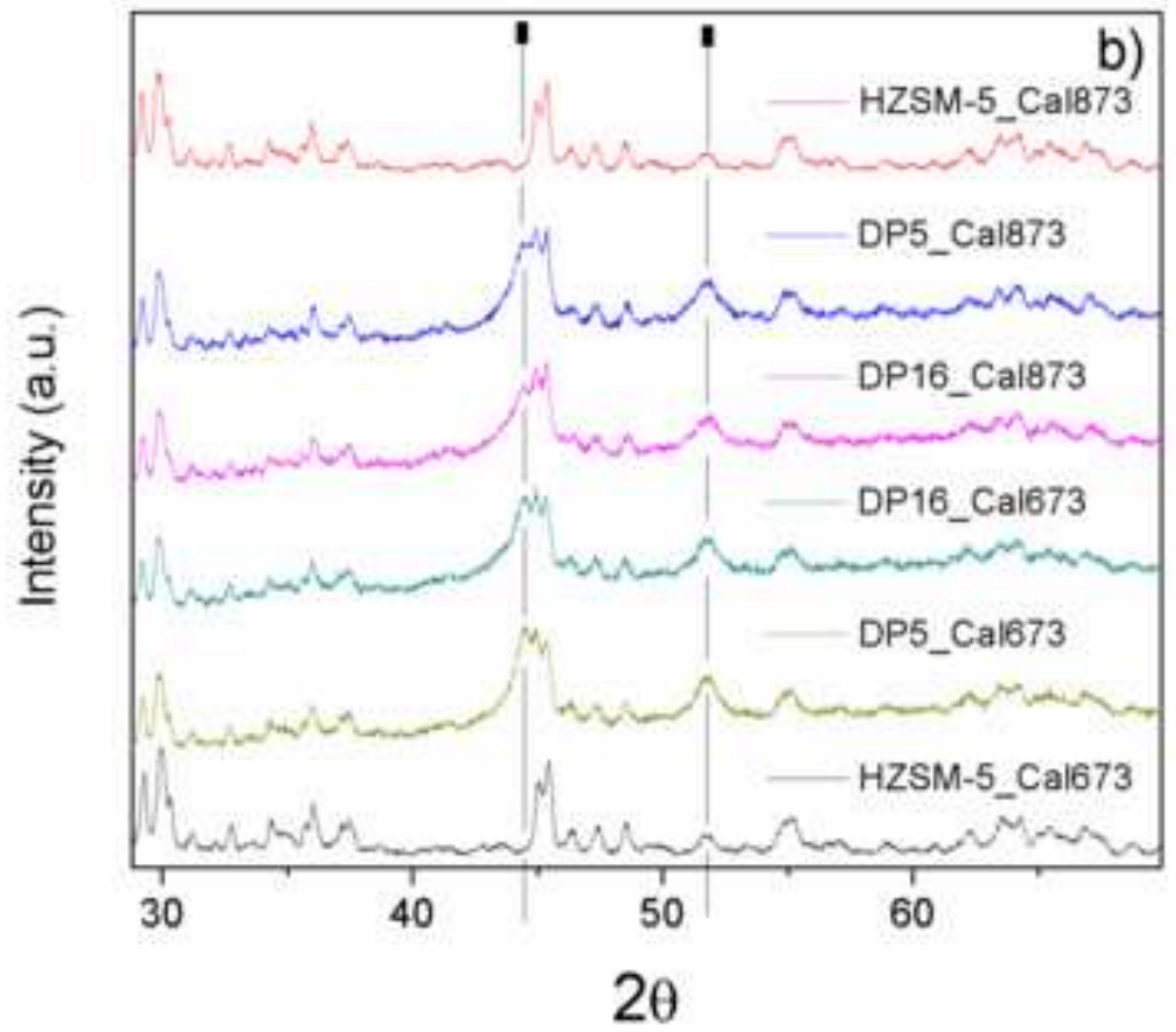




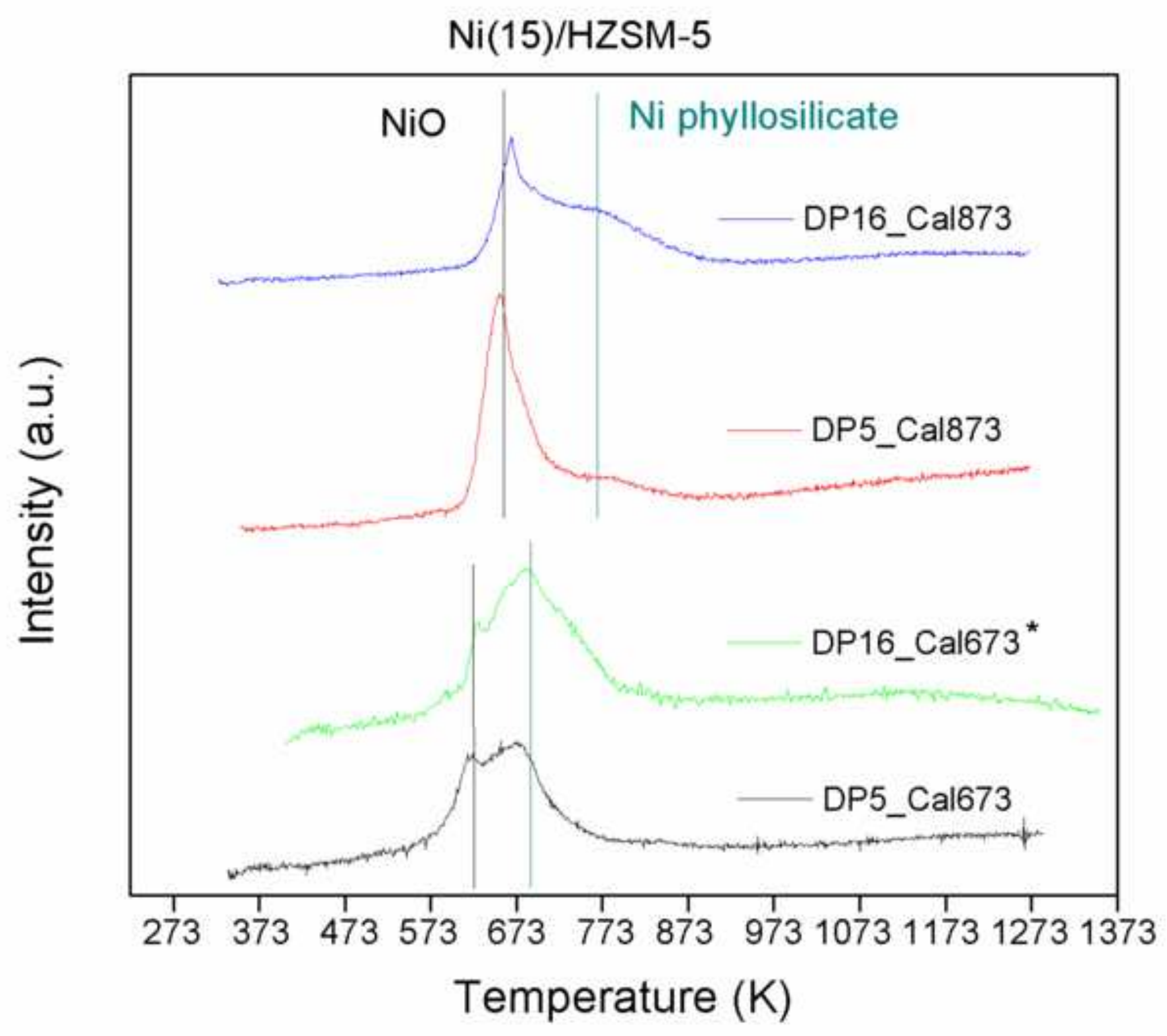

